\title{
Knockdown of circulating $\mathbf{C} 1$ inhibitor induces neurovascular impairment, glial cell activation, neuroinflammation, and behavioral deficits
}

\author{
Dorit Farfara $^{\mathrm{a}}$, Emily Feierman ${ }^{\mathrm{a}}$, Allison Richards ${ }^{\mathrm{a}}$, Alexey S. Revenko ${ }^{\mathrm{b}}$, Robert A. \\ MacLeod $^{\mathrm{b}}$, Erin H. Norris ${ }^{\mathrm{a}, 1}$, and Sidney Strickland ${ }^{\mathrm{a}, 1}$ \\ aPatricia and John Rosenwald Laboratory of Neurobiology and Genetics, The Rockefeller \\ University, New York, NY 10065, USA \\ bDepartment of Antisense Drug Discovery, IONIS Pharmaceuticals Inc, Carlsbad, CA, USA
}

\section{Abstract}

The cross-talk between blood proteins, immune cells, and brain function involves complex mechanisms. Plasma protein $\mathrm{C} 1$ inhibitor (C1INH) is an inhibitor of vascular inflammation that is induced by activation of the kallikrein-kinin system (KKS) and the complement system. Knockout of C1INH was previously correlated with peripheral vascular permeability via the bradykinin pathway, yet there was no evidence of its correlation with blood-brain barrier (BBB) integrity and brain function. In order to understand the effect of plasma C1INH on brain pathology via the vascular system, we knocked down circulating C1INH in wild-type (WT) mice using an antisense oligonucleotide (ASO), without affecting C1INH expression in peripheral immune cells or the brain, and examined brain pathology. Long-term elimination of endogenous C1INH in the plasma induced the activation of the KKS and peritoneal macrophages but did not activate the complement system. Bradykinin pathway proteins were elevated in the periphery and the brain, resulting in hypotension. BBB permeability, extravasation of plasma proteins into the brain parenchyma, activation of glial cells, and elevation of pro-inflammatory response mediators were detected. Furthermore, infiltrating innate immune cells were observed entering the brain through the lateral ventricle walls and the neurovascular unit. Mice showed normal locomotion function, yet cognition was impaired and depressive-like behavior was evident. In conclusion, our results highlight the important role of regulated plasma $\mathrm{C} 1 \mathrm{INH}$ as it acts as a gatekeeper to the brain via the neurovascular system. Thus, manipulation of $\mathrm{C} 1 \mathrm{INH}$ in neurovascular disorders might be therapeutically beneficial.

\section{Keywords}

C1 inhibitor; bradykinin; neurovascular; glia; neuroinflammation

\footnotetext{
${ }^{1}$ Corresponding Authors: Erin H. Norris and Sidney Strickland, enorris@ rockefeller.edu, strickland@ rockefeller.edu. Patricia and John Rosenwald Laboratory of Neurobiology and Genetics, The Rockefeller University, 1230 York Ave. New York, NY 10065, USA, 212-327-8705

Contributions: D.F. designed the study, performed experiments, analyzed data, and wrote the manuscript; E.F. and A.R. performed experiments and provided technical assistance; E.H.N and S.S participated in study design, data analysis, and manuscript preparation. Conflict-of-interest disclosure: Alexey S. Revenko and A. Robert MacLeod are employees and stockholders of Ionis Pharmaceuticals. The authors declare no additional competing financial interests.
} 


\section{Introduction}

$\mathrm{C} 1$ inhibitor (C1INH) is a circulating plasma protein, belonging to the super-family of serine protease inhibitors (serpins). It circulates in the plasma at the concentration of $0.15-0.3$ $\mathrm{mg} / \mathrm{ml}$ and is mainly produced by the liver. It inhibits the activation of the complement system (Ziccardi \& Cooper, 1979) and the kallikrein-kinin system (KKS) (Schapira, Scott, \& Colman, 1982), which share many inflammatory features mediated by the vascular system (Bossi, Peerschke, Ghebrehiwet, \& Tedesco, 2011; Ghebrehiwet, Kaplan, Joseph, \& Peerschke, 2016). Activation of the KKS through plasma kallikrein and high molecular weight kininogen (HK) induces secretion of a potent 9-amino acid peptide, bradykinin (Thompson, Mandle, \& Kaplan, 1978). Bradykinin causes vasodilation, reduces blood pressure, increases vascular permeability and cell recruitment, and induces proinflammatory responses by binding its receptors (Leeb-Lundberg, Marceau, Muller-Esterl, Pettibone, \& Zuraw, 2005; Schmaier \& McCrae, 2007). In the CNS, kinins are known neuromodulators involved in various inflammatory responses and blood-brain barrier (BBB) permeability(Borlongan \& Emerich, 2003; Hsieh, Wu, \& Yang, 2008; Levant, Levy, Argaman, \& Fleisher-Berkovich, 2006; Walker, Perkins, \& Dray, 1995).

The BBB is the first immune gate which maintains a homeostatic environment for resident brain cells such as neurons and glia. It is composed mainly of endothelial cells and tight junction proteins in collaboration with astrocytes, pericytes, and microglia/macrophages (Alvarez, Katayama, \& Prat, 2013). Evidence of plasma proteins in the brain suggests leakage and impairment of the BBB (Brightman, Klatzo, Olsson, \& Reese, 1970; Petersen, Ryu, \& Akassoglou, 2018), which contributes to neuroinflammation and autoimmune disorders such as Alzheimer's disease, Parkinson disease, and multiple sclerosis (Bennett et al., 2010; Ryu et al., 2015; Zlokovic, 2008).

Neuroinflammation is involved in many immune pathways (O'Callaghan, Sriram, \& Miller, 2008) and is tightly correlated with the vascular system (Grammas, 2011). Once activated by an immune trigger, immunocompetent glial cells such as astrocytes (Carpentier et al., 2005; Dong \& Benveniste, 2001) and microglia (Aloisi, 2001), upregulate cytokines, chemokines, and other recruiting signals (Becher, Prat, \& Antel, 2000; Farfara, Lifshitz, \& Frenkel, 2008). These released mediators locally diffuse into the bloodstream, attracting myeloid cells to the site of inflammation, and upregulate the expression of cellular adhesion molecules, which are necessary for attachment and transmigration across post-capillary venules (Engelhardt, 2008).

The correlation between C1INH and bradykinin was shown in a C1INH knockout mouse, where peripheral vascular permeability was induced through the activation of bradykinin 2 receptor (Han, MacFarlane, Mulligan, Scafidi, \& Davis, 2002), without any report of brain association. This knockout model mimics hereditary angioedema (HAE), characterized by acute peripheral inflammation in soft tissues, due to a genetic mutation in SERPING1, the gene for C1INH. Thus, we hypothesized that long-term reduced C1INH plasma levels would induce KKS activation towards vascular permeability, affecting the brain through the neurovascular system. To test this hypothesis, we knocked down the expression of 
circulating plasma $\mathrm{C} 1 \mathrm{INH}$ using an antisense oligonucleotide (ASO) and examined the brain for neurovascular impairment, neuroinflammation, and behavioral changes.

\section{Materials and Methods}

Animals.

All animal experiments were conducted in accordance with the guidelines of the US NIH Guide for the Care and Use of Laboratory Animals and with approval from the Animal Care and Use Committee of The Rockefeller University. C57/B16J males and females were used for all experiments. All cohorts were composed of both males and females. Data from males and females were compared in each experiment and showed no differences between sex in results, thus we pooled the data together. A second WT model, C57/C3H, was also used. Factor XII knockout (FXII-/-) mice, a gift from Thomas Renee, were backcrossed to C57BL/6 mice for $>10$ generations (Pauer et al., 2004). A total of five cohorts were used for the C57/B16J experiments (CTRL ASO vs C1INH ASO): Cohort 1 included 10 mice (4 CTRL ASO and 6 C1INH ASO), cohort $2-10$ mice (5 in each treated group), cohort $3-10$ mice (5 in each treated group), cohort $4-9$ mice (3 CTRL ASO and 6C1INH ASO), and cohort 5 - 13 mice (6 CTRL ASO and 7 C1INH ASO). Different animals from different cohorts were used in different experiments due to technical issues. Cohorts 1 and 2 were used for behavior tests. Cohort 5 was designated for vascular permeability assays. Two cohorts of $\mathrm{C} 57 / \mathrm{C} 3 \mathrm{H}$ were used for plasma evaluation and behavior. All measurements and blood collections were performed during the light cycle.

\section{ASO preparation and treatment.}

C1INH ASO (murine sequence) (Bhattacharjee et al., 2013) and control ASO (CTRL ASO, no homologies to the mouse genome) were provided by Ionis Pharmaceuticals. C1INH ASO and CTRL ASO were dissolved in saline and injected subcutaneously to ten-week-old mice at $150 \mathrm{mg} / \mathrm{kg} /$ week for the first two weeks (3 times a week at $50 \mathrm{mg} / \mathrm{kg}$ for two weeks) and then reduced to $50 \mathrm{mg} / \mathrm{kg} /$ week for 10 weeks (twice a week at $25 \mathrm{mg} / \mathrm{kg}$ for 10 weeks) ( $\mathrm{n}=6-14$ mice/group per cohort).

\section{Plasma processing.}

Plasma was always collected during the light cycle at three different time-points: the day before the treatment started, after two weeks of treatment with $150 \mathrm{mg} / \mathrm{kg} /$ week (submandibular), and the day of sacrifice (after 12 weeks, cardiac puncture). Animals were anesthetized at the end of the treatment using regulated CO2. Upon collection, blood was immediately processed in EDTA-containing tubes (BD Microtainer). Heparin was avoided as it has been shown to bind to C1INH (Rossi et al., 2010). Blood was centrifuged at 1300 rpm for $15 \mathrm{~min}$ at room temperature (RT). The upper phase of the supernatant was transferred to a second tube containing $0.5 \mathrm{M}$ EDTA ( $\mathrm{pH} 8$ ) and centrifuged again. The plasma was aliquoted and immediately frozen and stored at $-800 \mathrm{C}$ until analysis.

\section{Splenocytes and peritoneal macrophages.}

Splenocytes and intraperitoneal macrophages were extracted from CTRL ASO- and C1INH ASO-treated mice, and single-cell suspensions were prepared for FACS analysis (Farfara et 
al., 2011; Weiss, Lifshitz, \& Frenkel, 2011). In brief, to obtain intraperitoneal macrophage cells, we injected $15 \mathrm{ml}$ PBS to the peritoneal cavity and aspirated the fluid using a 31 gauge needle. To obtain splenocyte cells, we meshed the spleens using a syringe connected to a 70 $\mu \mathrm{m}$ cell strainer. The strainer was washed, and cells were reconstituted in RPMI medium. After centrifugation, the cells were immunostained with anti-CD4+ Cy7-conjugated and anti-CD8+ APC-conjugated antibodies (BD Bioscience) for T-cells and B-cells and antiF4/80 APC-conjugated and anti-CD11b PE-conjugated antibodies (BD Bioscience) for macrophages. Anti-SERPING1 conjugated FITC (Biorbyt; orb360810) was used to detect C1INH expression in specific cells.

\section{Kallikrein activity assay.}

Plasma was evaluated for KKS activity using the chromogenic substrate S-2303

(Diapharma) or Pefachrome PK8092 (Pentapharm) as previously demonstrated (Zamolodchikov, Chen, Conti, Renne, \& Strickland, 2015).

\section{LPS treatment.}

Mice were injected intraperitoneally with $100 \mu \mathrm{l}$ of $1 \mathrm{mg} / \mathrm{ml}$ lipopolysaccharide (LPS; L-2630 Sigma-Aldrich) during the dark cycle. Blood was collected and plasma was prepared 12 hours after LPS injection. LPS treated plasma was used as a positive control during all ELISA experiments.

\section{Alanine aminotransferase (ALT) activity assay.}

Liver enzyme function was examined using the ALT Activity Assay (MAK052, SigmaAldrich). As a positive control, we used LPS to induce high levels of secreted ALT levels in the plasma as previously shown(Baveja et al., 2002).

\section{Blood pressure.}

Blood pressure was measured at the end of ASO treatment using tail-cuff plethysmography (Kent Scientific) during light cycle.(Kruyer, Soplop, Strickland, \& Norris, 2015). An average of 3 readings was obtained for each animal during measurement.

\section{Immunohistochemistry.}

Fresh-frozen sections were fixed with either $50 \% \mathrm{MeOH}$ and $50 \%$ acetone for $10 \mathrm{~min}$ at $-20^{\circ} \mathrm{c}$ or $4 \%$ PFA. The primary antibodies used were: anti-GFAP (DAKO Z0334); antiCD11b (Abcam ab-8878); anti-TMEM (Abcam ab209064); anti-PECAM1 (BD Pharmingen 550274); anti-CD68 (AbD Serotec MCA1957GA); anti-CD206 (Thermo PA5-46994); antiFibrinogen (Dako A0080); IgG (Thermo scientific); anti-laminin (Fisher scientific RT-795PO); and anti-iNOS (Abcam ab-129372). For secondary antibodies, we used IgG (Thermo Scientific) from donkey anti- mouse, -rat, -rabbit or -goat, depending on the host of the primary antibody. Vectasheild-DAPI (Vector Labs) was used to seal the slides. Brain sections were visualized using Zeiss Axiovert200. Images were analyzed using ImageJ software. 


\section{Immunoblot.}

Immunoblotting was performed as described (Zamolodchikov, et al., 2015). Antibodies for plasma include: anti-C1INH (Proteintech 12259-1-AP); anti-HK light chain (R\&D

MAB22061); anti-FXII (HTI PAHFFXII-s); anti-plasma kallikrein (R\&D AF2498); antiC1qA (Thermo scientific PA5-29586); anti-C1r (Abcam ab66751); anti-C3a (Thermo scientific PA1-30601); and anti-transferrin (Abcam ab82411). All results were normalized to transferrin levels in plasma. Brain: anti-GFAP (DAKO Z0334); anti-CD11b (Abcam ab-133357); anti-B2R (LSBio LS-C405461); anti-iNOS (Abcam ab129372); anti-occludin (Invitrogen 33-1500); anti-GAPDH (Abcam ab9484 or Proteintech 60004-1-Ig); and antiactin (Sigma A5441 or Proteintech 60008-1-Ig). Protein levels were quantified using NIH Image $\mathbf{J}$ densitometry. All results for brain protein extracts were normalized to GAPDH or actin.

\section{ELISA.}

ELISA was used to determine level of C3a (Molecular Innovations) and bradykinin (ENZO) in plasma and brain homogenate (lower limits of detection are $0.1 \mathrm{ng} / \mathrm{ml}$ and $24.8 \mathrm{pg} / \mathrm{ml}$, respectively). The samples were normalized to $100 \%$ from CTRL-ASO to pool results from three different tests. For detection of pro-inflammatory cytokines from the brain we used (R\&D) Mouse DuoSet ELISA kits for IL-1 $\beta$, IL-6, and TNF- $\alpha$ (lower limits of detection are $15.6 \mathrm{pg} / \mathrm{mL}$ for IL- $1 \beta$ and IL- 6 and $31.3 \mathrm{pg} / \mathrm{mL}$ for TNF- $\alpha$ ). Plasma from LPS-injected mice was used as a positive control in these ELISA's as previously demonstrated (Qadri et al., 2016; Rothschild \& Gascon, 1966; Wu et al., 2016).

\section{Gene expression.}

RNA was extracted from fresh cortex or frozen whole brain using RNeasy Lipid Tissue mini kit (74804, Qiagen). RNA was converted to cDNA using High Capacity cDNA Reverse Transcription Kit (4368814, Life technologies). Gene expression levels were amplified using Taqman enzyme (Applied Biosystems, 4370048) and primers (SERPING1 Mm00437835_m1, IL1- $\beta$ Mm00434228_m1, IL-6 Mm00446190_m1, TNF- $a$ Mm00443258_m1, Bdkrb1 Mm04207315_s1, Bdkrb2 Mm00437788_s1, C3ar1 Mm01184110_m1, PECAM1 Mm01242576_m1, GFAPMm01253033_m1, CD11b Mm00434455_m1, and normalized to either endogenous mouse GAPDHMm99999915_g1 or $A C T B$ Mm02619580_g1. $\triangle \triangle C T$ was quantified and compared between samples.

\section{Evans blue and brain edema.}

Twelve hours before sacrifice, 2\% Evans blue in saline was injected into mice intraperitoneally. After perfusion with saline, one hemisphere was taken to assess percent $\mathrm{H} 2 \mathrm{O}$ volume using the wet/dry procedure (Hellal et al., 2004). Hemispheres were immediately weighed to obtain wet weight (WW) and heated to 1000C for 24h. Samples were then weighed to obtain the dry weight (DW). Brain water content was calculated as $\% \mathrm{H} 2 \mathrm{O}=(\mathrm{WW}-\mathrm{DW}) \mathrm{X} 100 / \mathrm{WW}$. The other brain hemisphere was collected and sectioned. Loss of BBB integrity was revealed by visualizing Evans blue by the fluorescence microscopy. 


\section{Tunnel assay.}

Cell death by apoptosis was examined using the In-Situ Cell Death Detection Kit, TMR red (Roche) following manufacturer's instructions.

\section{Behavioral analysis.}

All behavioral experiments were performed and analyzed by a researcher blind to genotype and treatment. 1) Fear conditioning was performed as previously described (Farfara et al., 2015 ) with some modifications. Two foot shocks were given ( 0.7 milliamp, $0.5 \mathrm{sec}$ ), one after the first three minutes and the second at the end of the five minutes of the first day. After 24 hours, mice were placed in the same chamber for 5 minutes without foot shock, and freezing time was measured. 2) Open field test was performed for 5 minutes as previously described (Gould TD, 2009). 3) Force swim test was performed in glass cylinders (height 30 $\mathrm{cm}$, diameter: $16 \mathrm{~cm}$ ) containing water at $24^{\circ} \mathrm{C}$ and depth of $14 \mathrm{~cm}$ as previously described(Seo, Zhong, Liu, Yan, \& Greengard, 2018).

\section{Statistical analysis.}

All statistical analyses were determined by two-tailed student t-test when two groups where compared. When multiple unpaired groups were compared, we used one-way ANOVA (Bonferroni post hoc test). PRISM software (GraphPad Software, La Jolla, CA, USA) was used to perform statistical analyses. All data are presented as mean \pm SEM. All experiments state the sample number as $\mathrm{n}=\mathrm{x}-\mathrm{y} /$ group ( $\mathrm{x}=\mathrm{CTRL}$ ASO, $\mathrm{y}=\mathrm{C} 1 \mathrm{INH}$ ASO) per group. Representative immunoblot images is based on at least three individual experiments of the number of subjects mentioned in the quantification. Representative immunostaining images are based on at least three stainings of consecutive sections. FACS experiments were performed in duplicate. Results with arbitrary units are presented as percent control when the experiments were not performed in the same time frame or were in different cohorts. Two experimental outliers were excluded from data analysis due to spontaneous death.

\section{Results}

\section{Knockdown of circulating C1INH activates KKS independent of FXII to produce bradykinin and induce hypotension.}

Based on the work of Bhattacharjee et al. (Bhattacharjee, et al., 2013) demonstrating the efficacy of ASO knockdown targeting circulating C1INH in the liver, we subcutaneously administered C1INH ASO and scrambled control ASO to ten-week-old C57/B16J male and female mice. After twelve weeks of treatment, we determined the levels of circulating C1INH protein expression in the plasma of treated mice and confirmed an $83 \%$ depletion compared to controls (Figure 1a-b). C1INH inhibits the activation of the KKS through fulllength, intact high molecular weight kininogen (iHK). When examining levels of iHK in mouse plasma (mHK), we observed a 50\% reduction in expression levels (mHK: $110 \mathrm{kDA}$ and mHK- $\triangle \mathrm{D} 5: 82 \mathrm{kDa}$, lacking domain 5), in C1INH ASO- compared to CTRL ASOtreated mice (Figure 1a-b), suggesting an increased level of cleaved HK (Zamolodchikov, et al., 2015). Similar results were obtained under non-reduced conditions (Supp. Figure 1a-d). Since plasma kallikrein cleaves iHK, we examined its levels and found significantly 
increased plasma kallikrein expression in plasma from C1INH ASO-treated mice compared to control (Figure 1a-b). We confirmed this occurrence in a different WT mouse strain, C57/ $\mathrm{C} 3 \mathrm{H}$, to ensure that these results were not strain-specific (Supp. Figure 1e-h). We also measured kallikrein activity using a chromogenic substrate assay (Zamolodchikov, et al., 2015) and found a significant increase in activity in plasma from C1INH ASO-treated mice compared to that of control mice (Figure 1c-d).

The KKS is normally initiated by activation of the contact system through coagulation factor 12 (FXII). However, activation of the HK/pre-kallikrein complex that generates kallikrein, bradykinin, and cleaved HK can occur even in the absence of FXII, and C1INH was shown to inhibit the pre-kallikrein cleavage of iHK (Joseph, Tholanikunnel, \& Kaplan, 2009). Interestingly, in our C1INH ASO-treated mice, plasma FXII expression did not differ, suggesting an independent mechanism of KKS activity induced by the depletion of C1INH protein. To determine if the activation of the KKS is FXII-dependent, we administered C1INH ASO to FXII-knockout mice. C1INH and iHK protein expressions were significantly reduced and plasma kallikrein was increased in FXII-knockout mice treated with C1INH ASO vs CTRL ASO, similar to the results obtained with WT mice (Figure 1e,f). Furthermore, the expression level of factor XI (FXI), a protease cleaved by FXIIa, did not differ in the plasma of WT treated groups (data not shown), supporting FXII-independent activation of the KKS.

The cleavage of iHK yields bradykinin, an unstable, rapidly degraded peptide. Using a sensitive ELISA, we found that levels of bradykinin were increased $23.4 \%$ in the plasma of C1INH ASO-treated mice compared to CTRL ASO-treated mice (Figure 1g). LPS-injected mice were used as positive controls, which demonstrated increased expression of the bradykinin pathway (data not shown)(Qadri, et al., 2016). Since bradykinin is known to lower blood pressure (Guilarte, Sala-Cunill, Luengo, Labrador-Horrillo, \& Cardona, 2017; Sala-Cunill et al., 2015; Waeber, Nussberger, Brunner, de Agostini, \& Schapira, 1984), we examined our mice and found a reduction in systolic, diastolic, and mean blood pressure in C1INH ASO- compared to CTRL ASO-treated mice (Figure 1h).

Since bradykinin can also activate peritoneal macrophages (Burch, Connor, \& Tiffany, 1989), we measured levels of F4/80 and CD11b using FACS. We found an increased activation of peritoneal macrophages in C1INH ASO-treated mice compared to CTRL mice (Figure 1i-k), suggesting that the depletion of C1INH activates innate immune cells in the periphery. We also checked the level of C1INH in this macrophage population and found it to be increased by $64 \%$ (Supp. Figure 2a-b), suggesting the ASO treatment targeted only the liver-secreted form of CINH protein and did not affect protein expression in macrophages. We further examined levels of $\mathrm{C} 1 \mathrm{INH}$ in $\mathrm{CD} 4+$ and $\mathrm{CD} 8+$ cells from the spleen, as a possible consequence of C1INH ASO treatment and found no differences between the treated groups (Supp. Figure 2c-e), suggesting the C1INH ASO had not knocked-down the protein expression in either innate or adaptive immune cells. In order to rule out liver toxicity as a possible outcome of the ASO treatment we examined levels of alanine aminotransferase (ALT) and found no differences in plasma between the treated groups (Supp. Figure 3a). We then analyzed the activation of the adaptive immune response as a possible toxic outcome and there was no evidence of increased adaptive immune response 
by $\mathrm{T}$ cell and B cell or spleen enlargement (Supp. Figure 3b-e), indicating no immune toxicity.

C1INH is mainly known as an inhibitor of the complement system, however we found no changes in classical complement activation proteins measured by immunoblots and ELISA for C1qA, C1r, and C3a (Supp. Figure 4a-g), suggesting that the depletion of circulating C1INH leads to the activation of the KKS without involvement of the complement system activation.

\section{Knockdown of circulating C1INH increases bradykinin-pathway receptors in the brain and mediates BBB permeability.}

As a potent vasodilator, bradykinin induces BBB permeability (Inamura \& Black, 1994; Olesen \& Crone, 1986; Sanovich et al., 1995) and mediates a pro-inflammatory response in the nervous system through its receptors (Raslan et al., 2010). We found significant increases in gene expression of bradykinin 1 receptor $(B 1 R)$ and bradykinin 2 receptor $(B 2 R)$ in the brains of C1INH ASO- vs. CTRL ASO-treated mice (Figure 2a). Moreover, $\mathrm{B} 2 \mathrm{R}$ protein expression was increased two-fold in cortices of C1INH ASO mice compared to controls (Figure 2b-c), suggesting an elevated activation of the bradykinin pathway in the brain. Next, we examined endothelial cell expression since these cells are major components of the BBB. Using endothelial cell markers CD31 and PECAM1, we found decreased expression in the CA1 region of the hippocampus in C1INH ASO- vs. CTRL ASO-treated mice (Figure 2d-f). It has been shown that PECAM-1-deficient endothelial cells enhance permeability of the BBB(Graesser et al., 2002), which prompted us to further examine BBB integrity in our mice. We found that occludin, a tight-junction protein that degrades with increased BBB permeability(Schubert-Unkmeir et al., 2010), was also decreased in C1INH ASO- mice compared to CTRL ASO-treated mice (Figure 2g-h). Furthermore, at the end of the chronic ASO treatment, we used Evans blue to examine BBB integrity of CTRL ASOand C1INH ASO-treated mice. We found an increased blue staining in the freshly frozen brains of C1INH ASO mice compared to CTRL ASO, specifically in the ventricles and the interstitial spaces (Figure 2i-j). Moreover, Evans blue dye was detected by fluorescence microscopy in the brain tissue of C1INH ASO mice but not CTRL ASO, specifically in the margins of the lateral ventricle (Figure 2k). In addition, fibrin(ogen) and IgG (Petersen, et al., 2018) showed extensive extravasation from blood vessels in the areas around the lateral ventricle, fimbria, and CA1 and CA3 regions of the hippocampus of C1INH ASO compared to CTRL ASO-treated mice (Figure 21-m). Whole brains were examined for edema by measuring water content, and did not find any differences between treated groups (Supp. Figure 5). These results suggest that peripheral C1INH depletion leads to dysregulation of endothelial cells and loss of BBB integrity.

\section{Increased activation of resident glia towards a pro-inflammatory response.}

Astrocytes and microglia are the resident immune cells of the brain (Aloisi, 2001; Dong \& Benveniste, 2001), and along with neurons and vascular cells they comprise the neurovascular unit (NVU) (Iadecola, 2004). Upon activation, they secrete pro- and antiinflammatory cytokines depending on the immune trigger (Farfara, et al., 2008), which contributes to BBB permeability and infiltration of peripheral immune cells (Erickson, Dohi, 
$\&$ Banks, 2012). We examined activation of astrocytes and myeloid cells by analyzing GFAP and CD11b levels, respectively. We found significant up-regulation of both genes and proteins in the cortex of C1INH ASO-treated mice compared to CTRL ASO-treated mice (Figure 3a-c). We confirmed these results by immunofluorescence (Figure 4d). To understand whether this activation was towards a pro-inflammatory or a neuroprotective response, we measured the mRNA profile of pro-inflammatory cytokines such as $I L-1 \beta$, $T N F-a$ and $I L-6$. Comparing brain samples from C1INH ASO- and CTRL ASO-treated mice, RT-PCR analysis (Figure 3e) showed an increase in pro-inflammatory cytokine gene expression, and ELISA (Figure 3f-h) showed an increase in proteins levels. Furthermore, since nitric oxide (NO) is known to be secreted from activated resident immune cells during a pro-inflammatory response, we used immunofluorescence staining (Figure 3i) and immunoblotting (Figure 3j) to examine changes in inducible synthase (iNOS). We observed an increase in iNOS expression in brains of C1INH ASO mice compared to CTRL ASOtreated mice (Figure 3i-k). Interestingly, SERPING1 mRNA (Figure 31) and C1INH protein (Figure 3m-n) levels in the brains of C1INH ASO-treated mice were highly elevated compared to CTRL ASO-treated mice. Therefore, while ASO treatment depleted peripheral production of C1INH (Figure 1a), it did not affect brain levels of C1INH. The elevation of C1INH observed here might be the result of a compensatory mechanism towards an increased pro-inflammatory response. To determine any involvement of the classical complement system in the brain, we examined levels of C3a and C3aR1 by ELISA and RTPCR and found no differences (Supp. Figure 6 a,b).

\section{Knockdown of circulating C1INH increases levels of infiltrating myeloid cells in the brains of C1INH ASO-treated mice.}

The brain is constantly monitored by resident and infiltrated innate immune cells, thus we focused on the circumventricular organs (CVOs) which are located around the ventricles and are areas where the blood, cerebrospinal fluid (CSF), and brain parenchyma come into contact. Resident microglia can be distinguished from infiltrating macrophages using the homeostatic marker TMEM119 (Satoh et al., 2016) and overall morphology (Shechter et al., 2009). In order to evaluate the immune response in the brain as a result of $\mathrm{C} 1 \mathrm{INH}$ knockdown, we used CD11b and CD68, markers of phagocytic myeloid cells, and TMEM119, specific marker of homeostatic microglial cells. We identified resident microglia as those co-localizing with CD11b and TMEM119 (CD11b+/TMEM119+) vs. infiltrating myeloid cells which express CD68 or CD11b but not TMEM119 (CD68+/TMEM- or CD11b+/TMEM-). We examined the general population of cells in the lateral ventricle (LV) of our mice. Within the choroid plexus (CP) of CTRL-ASO mice, there was intense staining of CD68 and CD11b cells, which were negative for TMEM119. These results agree with published data indicating blood-derived macrophages populate the ventricles (Figure 4a and b). Moreover, the morphology of these CD68+/TMEM- and CD11b+/TMEM- cells in the LV were defined by large cell bodies with small processes. The cell morphology of resident microglial cells, those that co-express CD11b and TMEM119, surrounding the LV and the fimbria of the hippocampus, were comprised of smaller cell bodies and longer processes (Figure 4c). We determined that most of the cells highly expressing CD68 were either in the LV or bordered by astrocytes (stained with anti-GFAP antibody) around cerebral blood vessels (Figure 4b and Supp. Figure 7), indicating that they were not resident immune cells. 
Perivascular macrophages (PVM) are mostly located in the perivascular spaces surrounding arteries and veins throughout the brain tissue (Faraco, Park, Anrather, \& Iadecola, 2017) and are elevated in brain disorders (Faraco, et al., 2017). In order to distinguish between bloodderived infiltrating macrophages and PVMs, we identified cells that co-expressed CD206 and CD68 (CD206+/CD68+). We identified CD206+/CD68+ cells in the perivascular space and LV of CTRL-ASO brains, which were all negative to TMEM119, suggesting these cells were not resident but perivascular macrophages instead (Supp. Figure 8). We observed decreased staining of CD68 cells with round-shaped bodies, identified as infiltrated macrophages, surrounding the $\mathrm{CP}$ and in the $\mathrm{LV}$ of C1INH ASO-treated mice compared to CTRL ASO-treated mice (Figure 4f). Conversely, increased staining of CD68 was evident along the walls of the LV and perivascular space of C1INH ASO- vs CTRL ASO-treated mice (Figure 4d-e), suggesting recruitment of infiltrated macrophages to the brain through the vasculature.

Moreover, throughout the brains of C1INH ASO-treated mice we found more CD68+ cells and CD206- cells in the wall of the LV (Figure 5a), parenchyma (Figure 5b), and areas of white matter such as the optic tract (Figure 5c-d). These findings suggest increased infiltration of non-resident (CD11b+/TMEM-) macrophages, which are not of perivascular origin (CD206-), in the brains of C1INH ASO-treated mice.

\section{Knockdown of circulating C1INH in WT mice resulted in behavioral deficits.}

We measured locomotive function and learning and memory behaviors of the ASO-treated mice. By measuring distance traveled on Day 1 of the fear conditioning test prior to the foot shock, we found no locomotive activity differences between the mouse groups (Figure 6a). Furthermore, C1INH ASO-treated mice showed no difference in freezing time on Day 1 after receiving the electric shock compared to the CTRL ASO group (Figure 6b). However, C1INH ASO-treated mice showed a reduction in total freezing time (Figure 6c) on the test day (Day 2), suggesting impairment in learning and memory. An open field test was also used to compare the average distance each mouse traveled over a day and found no differences between the treated groups (Figure 6d). Of note, we did not observe any differences in anxiety levels based on the amount of time spent in the inner zones of the arena or the number of times crossing the arena (data not shown). Forced swim test (FST) was used to evaluate depressive-like behavior in these mice. We found a significant increase in time spent immobile in C1INH ASO-treated mice compared to CTRL ASO-treated mice, suggesting that prolonged reduced levels of C1IHN may induce depressive-like behavior (Figure 6e). Although cognitive impairment is often correlated with neurodegeneration(Haass, 1999), we did not observe apoptotic cell degeneration measured by TUNEL (Supp. Figure 9).

\section{Discussion}

We are the first to demonstrate that depletion of endogenous circulating immune plasma protein C1INH in WT mice leads to brain inflammation and behavioral deficits by way of the vascular kinin pathway. Specifically, long-term depletion of peripheral C1INH by ASO in mice led to activation of the KKS, increased HK cleavage, and bradykinin generation in 
the periphery, which subsequently decreased BBB integrity and led to infiltration of peripheral monocyte-derived cells into the brain, activated glial cells towards a proinflammatory response, and induced behavioral deficits.

Our knockdown mouse model partially mimics the clinical pathology of hereditary angioedema (HAE) type-1 and acquired angioedema (AAE), conditions caused by depletion, impairment, or degradation of C1INH in humans. HAE type-1 and AAE are diseases characterized by recurrent episodes of severe, localized inflammation and increased vascular permeability affecting soft tissues, including the gastrointestinal tract, upper airways, and the mucosa (Agostoni \& Cicardi, 1992; Carugati, Pappalardo, Zingale, \& Cicardi, 2001). C1INH knockout mice have peripheral vascular permeability mediated by the bradykinin pathway, correlating to the HAE condition. However, the neurovascular system affected by C1INH impairment was never examined and brain pathology was not evaluated in this knockout mouse model. It is important to note that migraines, stroke, cerebral symptoms, blindness, tetraspasticity, and other irreversible brain damage can also occur in HAE (Bonnaud et al., 2012; Bork et al., 2017; Chung \& Kim, 2012; Lasek-Bal, Holecki, Handzlik-Orlik, Smertka, \& Dulawa, 2015; Neri, 2014). Moreover, HAE patients sometimes manifest with depression and anxiety (Fouche, Saunders, \& Craig, 2014). Thus, we hypothesized that impairment of circulating C1INH protein would affect the neurovascular system and the brain.

In order to examine the effect of endogenous C1INH on the neurovascular system and the brain, we used ASO technology to deplete nearly all circulating C1INH. By reducing the normal levels of C1INH in the plasma of WT mice, we induced the activation of the KKS, which led to high levels of bradykinin and thus hypotension. Since C1INH ASO targets the liver (Bhattacharjee, et al., 2013), it was important for us to determine any possible toxic effects in the periphery that might be caused by the long-term treatment. We found no evidence of liver toxicity, nor did we find reduced expression of innate and adaptive immune cells in the periphery. However, in the brains of C1INH ASO-treated mice, C1INH was upregulated, possibly as a result of the induced neuroinflammation.

Similar to our results in C1INH ASO-treated mice, plasma from C1INH-deficient patients contains decreased levels of iHK (Schapira et al., 1983). During inflammatory attacks, HK is cleaved (Berrettini et al., 1986) and bradykinin is released (Nussberger et al., 1998). The severe swelling of soft tissues and inflammation is contributed by vascular permeability. The inflammatory acute attacks in HAE patients are mediated by the activation of the KKS along with complement system activation (Bossi, et al., 2011; Nielsen et al., 1996). Interestingly, the complement system was quiescent in our knockdown mouse model of C1INH, suggesting that the severe acute attacks HAE patients experience are not induced only by reduced or impaired C1INH protein levels, but by physiological stress or another immune trigger (Nielsen et al., 1995) that involves the contribution of the complement system along with the KKS. Today, HAE patients are treated with either recombinant C1INH or kallikrein inhibitors (Cugno, Zanichelli, Foieni, Caccia, \& Cicardi, 2009; Sabharwal \& Craig, 2015) to normalize the inflammatory effect caused by bradykinin activation. 
In our study, depletion of circulating C1INH led to decreased blood pressure likely due to the activation of the bradykinin pathway in the plasma and brain, which causes blood vessels to dilate. It was previously shown that hypoperfusion caused BBB breakdown and further induced glial cell activation and memory deficits (Wang et al., 2016). Supporting this result, we report here that the impairment of the vasculature is evident in the brains of the C1INH ASO-treated mice as well as in the periphery. We show evidence of a BBB integrity loss in C1INH ASO-treated mice, mediated by decreased expression of critical vascular components of the intact BBB and plasma protein extravasation into the brain parenchyma. Fibrinogen extravasation and deposition in the brain has been shown to recruit peripheral macrophages, induce neuroinflammation, and mediate brain disorders (Paul, Strickland, \& Melchor, 2007; Petersen, et al., 2018; Ryu, et al., 2015). BBB dysfunction is also known to induce the activation of resident glial cells. Beyond the decreased expression we observed in vascular glial cells and tight junction proteins, resident microglia and astrocytes became activated towards a pro-inflammatory response as indicated by elevated levels of IL- $1 \beta$, IL-6, TNF-a, and iNOS in the brains of C1INH ASO-treated mice.

Neuroinflammation and cognitive decline correlate with increased peripheral immune cell activation (Hu, Ou, Duan, \& Jiang, 2010; Obasi et al., 2012; Simen, Bordner, Martin, Moy, $\&$ Barry, 2011). Infiltration of peripheral immune cells to the CNS under inflammatory conditions is mediated by migration through the ventricular wall into the perivascular spaces and across the glia lamitans penetrating the parenchyma (Owens, Bechmann, \& Engelhardt, 2008). Due to the unique structure of the CVO's, the passage of large substances and cells from the blood to the perivascular spaces and parenchyma is possible, and the brain is exposed to peripheral signals (Siso, Jeffrey, \& Gonzalez, 2010). The CP, known to be one of the CVOs, has fenestrated capillaries, which allows it to act as a selective gate for transmigrating immune cells into the brain (Wilson, Weninger, \& Hunter, 2010). The CP, which also produces CSF, is abundant in myeloid cells that function as immunosurveillance cells in health and disease (Kaur, Rathnasamy, \& Ling, 2016). Infiltrated myeloid cells exhibit enhanced phagocytic capacity, neurotrophic support, and anti-inflammatory characteristics compared to resident microglia (London, Cohen, \& Schwartz, 2013; Shechter, et al., 2009) (Ginhoux et al., 2010). In the brains of C1INH ASO-treated mice, we observed accumulation of infiltrating myeloid-derived cells in the brain. Specifically, upon examination of the $\mathrm{CP}$ and the $\mathrm{LV}$ of brains from C1INH ASO-treated mice, we found decreased levels of infiltrating myeloid-derived macrophages, as determined by CD68+/ CD11b+/TMEM119- staining, suggesting they are not resident microglia. However, these peripheral innate immune cells seemed to infiltrate from the $\mathrm{CP}$ to the ventricle wall through the vasculature, entering different parts of the brain parenchyma, white matter, and optic tract. These cells were also negative for CD206, a marker expressed on perivascular macrophages, suggesting they are of different origin. We determined a significant activation of peritoneal macrophages in C1INH ASO treated-mice compared to the control groups. Interestingly, in a multiple sclerosis mouse model (EAE), Ly-6C was used to differentiate activated myeloid-derived cells from resident microglia, and these peripheral cells were suggested to infiltrate into the brains while microglia remained inactivated(Vainchtein et al., 2014), indicating that the elevation of CD11b that we observed is more likely due to myeloid-derived cell infiltration than microglia activation. Of note, TMEM119 is a marker 
of homeostatic microglia, yet it does not correlate with activated microglial states, making it even more difficult to distinguish between activated myeloid-derived cells and yolk sacderived microglia. It is suggested that recruited peripheral immune cells can be either protective or detrimental, depending on the immune trigger (Rezai-Zadeh, Gate, \& Town, 2009). Nevertheless, it is agreed that acute inflammation is crucial for protection and repair, as opposed to chronic inflammation, which might lead to toxic fallout.

Systemic inflammation can induce neuroinflammation and behavioral deficits such as depressive-like behavior and cognitive impairment (Benson et al., 2017; Biesmans et al., 2015; Biesmans et al., 2013). Moreover, emerging evidence correlates cognitive impairment and psychologic behaviors (Cabrera et al., 2016; Caceda, Griffin, \& Delgado, 2018). It also has been suggested that blood proteins and impairments of the NVU can be mediators of cognitive dysfunction (Mogi \& Horiuchi, 2011; Taheri et al., 2011; Takechi et al., 2017). When we compared cognition between the treated mouse groups, we found a significant cognitive deficit in C1INH ASO-treated mice compared to control mice. We also observed significantly more immobility in C1INH ASO-treated mice, suggesting long-term depletion of C1INH induced depression-like behavior.

As a major nerve of the parasympathetic division of the autonomic nervous system, the vagus nerve innervates the liver, lungs, spleen, kidneys, and gut. It is a crucial mediator of the innate immune response and inflammation (Tracey, 2016). Therefore, we cannot exclude a possible effect of the vagus nerve on the results presented here.

Treatment with C1INH has proven beneficial to mice and humans in a variety of inflammatory conditions such as HAE, sepsis, myocardial ischemia-reperfusion injury, brain injury, xenograph transplant rejection, and hemorrhagic shock (Caliezi et al., 2000) (Akita, Nakase, Kaido, Kanemoto, \& Sakaki, 2003; Horstick et al., 1997) (Croner et al., 2004; Guerrero et al., 1993; Jansen et al., 1998; Scherer, Giebler, Schmidt, Paar, \& Kox, 1996) (Fiane et al., 1999; Hecker, Loss, Klempnauer, \& Winkler, 2002) (Horstick et al., 2001) (Niederau et al., 1995; Tassani et al., 2001). C1INH has also been shown to be therapeutically beneficial in humans after coronary and myocardial infarction(Bauernschmitt, Bohrer, \& Hagl, 1998; de Zwaan et al., 2002), septic shock, and vascular leak syndrome (Hack et al., 1993). Moreover, mice infected with Streptococcus pneumonia and then treated with C1INH showed bacterial clearance in the cerebrospinal fluid (CSF) and blood, decreased leukocyte infiltration to the CSF, recovery of meningitis, and reduced IL-6 levels (Zwijnenburg et al., 2007). Administration of C1INH was shown to have neuroprotective roles in neurovascular diseases such as stroke and traumatic brain injury by reducing the infarct volume and the neuronal damage in the temporal cortex, striatum, hippocampus, and thalamus (Albert-Weissenberger et al., 2014; De Simoni et al., 2003; Heydenreich et al., 2012).

Our data suggest that long-term depletion of circulating endogenous $\mathrm{C} 1 \mathrm{INH}$ can cause neurovascular dysfunction, neuroinflammation, and behavioral deficits mediated by the activation of the KKS in the circulation. Treatment with recombinant C1INH, KKS inhibitors, or B2R antagonists might be considered as prophylactic and/or long-term treatments for neurovascular disorders involving neuroinflammation. Furthermore, 
manipulation of C1INH levels in the periphery could be considered to intentionally open the BBB for drug administration.

\section{Supplementary Material}

Refer to Web version on PubMed Central for supplementary material.

\section{Acknowledgements:}

The authors thank members of the Strickland laboratory, Dr. Shiri Gur Cohen, and Dr. Gali Umschweiff for their help. This work was supported by the EGL Charitable Foundation; NIH; Cure Alzheimer's Fund; Alzheimer's Association; Rudin Family Foundation; Mellam Family Foundation; and Mr. John A. Herrmann, Jr.

\section{References}

Agostoni A, \& Cicardi M (1992). Hereditary and acquired C1-inhibitor deficiency: biological and clinical characteristics in 235 patients. Medicine (Baltimore), 71(4), 206-215. [PubMed: 1518394]

Akita N, Nakase H, Kaido T, Kanemoto Y, \& Sakaki T (2003). Protective effect of C1 esterase inhibitor on reperfusion injury in the rat middle cerebral artery occlusion model. Neurosurgery, 52(2), 395-400; discussion 400-391. [PubMed: 12535370]

Albert-Weissenberger C, Mencl S, Schuhmann MK, Salur I, Gob E, Langhauser F, . . Kleinschnitz C (2014). C1-Inhibitor protects from focal brain trauma in a cortical cryolesion mice model by reducing thrombo-inflammation. Front Cell Neurosci, 8, 269. doi: 10.3389/fncel.2014.00269 [PubMed: 25249935]

Aloisi F (2001). Immune function of microglia. Glia, 36(2), 165-179. doi: 10.1002/glia.1106 [pii] [PubMed: 11596125]

Alvarez JI, Katayama T, \& Prat A (2013). Glial influence on the blood brain barrier. Glia, 61(12), 1939-1958. doi: 10.1002/glia.22575 [PubMed: 24123158]

Bauernschmitt R, Bohrer H, \& Hagl S (1998). Rescue therapy with C1-esterase inhibitor concentrate after emergency coronary surgery for failed PTCA. [Case Reports]. Intensive Care Med, 24(6), 635638. [PubMed: 9681790]

Baveja R, Keller S, Yokoyama Y, Sonin N, Clemens MG, \& Zhang JX (2002). LPS-induced imbalanced expression of hepatic vascular stress genes in cirrhosis: possible mechanism of increased susceptibility to endotoxemia. Shock, 17(4), 316-321. [PubMed: 11954834]

Becher B, Prat A, \& Antel JP (2000). Brain-immune connection: immuno-regulatory properties of CNS-resident cells. Glia, 29(4), 293-304. doi: 10.1002/ (SICI)1098-1136(20000215)29:4<293::AID-GLIA1>3.0.CO;2-A [pii] [PubMed: 10652440]

Bennett J, Basivireddy J, Kollar A, Biron KE, Reickmann P, Jefferies WA, \& McQuaid S (2010). Blood-brain barrier disruption and enhanced vascular permeability in the multiple sclerosis model EAE. Journal of Neuroimmunology, 229(1-2), 180-191. doi: 10.1016/j.jneuroim.2010.08.011 [PubMed: 20832870]

Benson S, Brinkhoff A, Lueg L, Roderigo T, Kribben A, Wilde B, . . Elsenbruch S (2017). Effects of acute systemic inflammation on the interplay between sad mood and affective cognition. Transl Psychiatry, 7(12), 1281. doi: 10.1038/s41398-017-0043-0 [pii] [PubMed: 29225332]

Berrettini M, Lammle B, White T, Heeb MJ, Schwarz HP, Zuraw B, . . Griffin JH (1986). Detection of in vitro and in vivo cleavage of high molecular weight kininogen in human plasma by immunoblotting with monoclonal antibodies. Blood, 68(2), 455-462. [PubMed: 3730610]

Bhattacharjee G, Revenko AS, Crosby JR, May C, Gao D, Zhao C, ... MacLeod AR (2013). Inhibition of vascular permeability by antisense-mediated inhibition of plasma kallikrein and coagulation factor 12. Nucleic Acid Ther, 23(3), 175-187. doi: 10.1089/nat.2013.0417 [PubMed: 23582057]

Biesmans S, Bouwknecht JA, Ver Donck L, Langlois X, Acton PD, De Haes P, . . Nuydens R (2015). Peripheral Administration of Tumor Necrosis Factor-Alpha Induces Neuroinflammation and 
Sickness but Not Depressive-Like Behavior in Mice. Biomed Res Int, 2015, 716920. doi: 10.1155/2015/716920 [PubMed: 26290874]

Biesmans S, Meert TF, Bouwknecht JA, Acton PD, Davoodi N, De Haes P, . . Nuydens R (2013). Systemic immune activation leads to neuroinflammation and sickness behavior in mice. Mediators Inflamm, 2013, 271359. doi: 10.1155/2013/271359 [PubMed: 23935246]

Bonnaud I, Rouaud V, Guyot M, Debiais S, Saudeau D, de Toffol B, \& Farber CM (2012). Exceptional stroke-like episodes in a patient with type I autosomal angioedema. Neurology, 78(8), 598-599. doi: 10.1212/WNL.0b013e318247ca58 [PubMed: 22323759]

Bork K, Brehler R, Witzke G, Boor S, Heineke W, \& Hardt J (2017). Blindness, tetraspasticity, and other signs of irreversible brain damage in hereditary angioedema. Ann Allergy Asthma Immunol, 118(4), 520-521. doi: S1081-1206(17)30098-4 [pii] 10.1016/j.anai.2017.01.027 [PubMed: 28279594]

Borlongan CV, \& Emerich DF (2003). Facilitation of drug entry into the CNS via transient permeation of blood brain barrier: laboratory and preliminary clinical evidence from bradykinin receptor agonist, Cereport. Brain Research Bulletin, 60(3), 297-306. doi: S0361923003000431 [pii] [PubMed: 12754091]

Bossi F, Peerschke EI, Ghebrehiwet B, \& Tedesco F (2011). Cross-talk between the complement and the kinin system in vascular permeability. [Research Support, N.I.H., Extramural Review]. Immunol Lett, 140(1-2), 7-13. doi: 10.1016/j.imlet.2011.06.006 [PubMed: 21762728]

Brightman MW, Klatzo I, Olsson Y, \& Reese TS (1970). The blood-brain barrier to proteins under normal and pathological conditions. J Neurol Sci, 10(3), 215-239. doi: 0022-510X(70)90151-6 [pii] [PubMed: 4909727]

Burch RM, Connor JR, \& Tiffany CW (1989). The kallikrein-kininogen-kinin system in chronic inflammation. Agents Actions, 27(3-4), 258-260. [PubMed: 2801307]

Cabrera B, Bioque M, Penades R, Gonzalez-Pinto A, Parellada M, Bobes J, . . Bernardo M (2016). Cognition and psychopathology in first-episode psychosis: are they related to inflammation? Psychol Med, 46(10), 2133-2144. doi: 10.1017/S0033291716000659 [PubMed: 27055381]

Caceda R, Griffin WST, \& Delgado PL (2018). A probe in the connection between inflammation, cognition and suicide. J Psychopharmacol, 32(4), 482-488. doi: 10.1177/0269881118764022 [PubMed: 29552947]

Caliezi C, Wuillemin WA, Zeerleder S, Redondo M, Eisele B, \& Hack CE (2000). C1-Esterase inhibitor: an anti-inflammatory agent and its potential use in the treatment of diseases other than hereditary angioedema. Pharmacol Rev, 52(1), 91-112. [PubMed: 10699156]

Carpentier PA, Begolka WS, Olson JK, Elhofy A, Karpus WJ, \& Miller SD (2005). Differential activation of astrocytes by innate and adaptive immune stimuli. Glia, 49(3), 360-374. doi: 10.1002/glia.20117 [PubMed: 15538753]

Carugati A, Pappalardo E, Zingale LC, \& Cicardi M (2001). C1-inhibitor deficiency and angioedema. [Review]. Mol Immunol, 38(2-3), 161-173. [PubMed: 11532278]

Chung JY, \& Kim M (2012). Migraine-like headache in a patient with complement 1 inhibitor deficient hereditary angioedema. J Korean Med Sci, 27(1), 104-106. doi: 10.3346/jkms.2012.27.1.104 [PubMed: 22219624]

Croner RS, Lehmann TG, Fallsehr C, Herfarth C, Klar E, \& Kirschfink M (2004). C1-inhibitor reduces hepatic leukocyte-endothelial interaction and the expression of VCAM-1 in LPS-induced sepsis in the rat. Microvasc Res, 67(2), 182-191. doi: 10.1016/j.mvr.2003.09.009 [PubMed: 15020209]

Cugno M, Zanichelli A, Foieni F, Caccia S, \& Cicardi M (2009). C1-inhibitor deficiency and angioedema: molecular mechanisms and clinical progress. Trends Mol Med, 15(2), 69-78. doi: 10.1016/j.molmed.2008.12.001 S1471-4914(09)00014-8 [pii] [PubMed: 19162547]

De Simoni MG, Storini C, Barba M, Catapano L, Arabia AM, Rossi E, \& Bergamaschini L (2003). Neuroprotection by complement $(\mathrm{C} 1)$ inhibitor in mouse transient brain ischemia. J Cereb Blood Flow Metab, 23(2), 232-239. [PubMed: 12571454]

de Zwaan C, Kleine AH, Diris JH, Glatz JF, Wellens HJ, Strengers PF, . . Hermens WT (2002). Continuous 48-h C1-inhibitor treatment, following reperfusion therapy, in patients with acute myocardial infarction. Eur Heart J, 23(21), 1670-1677. [PubMed: 12398824] 
Dong Y, \& Benveniste EN (2001). Immune function of astrocytes. Glia, 36(2), 180-190. doi: 10.1002/ glia.1107 [pii] [PubMed: 11596126]

Engelhardt B (2008). Immune cell entry into the central nervous system: involvement of adhesion molecules and chemokines. J Neurol Sci, 274(1-2), 23-26. doi: 10.1016/j.jns.2008.05.019 S0022510X(08)00250-5 [pii] [PubMed: 18573502]

Erickson MA, Dohi K, \& Banks WA (2012). Neuroinflammation: a common pathway in CNS diseases as mediated at the blood-brain barrier. Neuroimmunomodulation, 19(2), 121-130. doi: 10.1159/000330247000330247 [pii] [PubMed: 22248728]

Faraco G, Park L, Anrather J, \& Iadecola C (2017). Brain perivascular macrophages: characterization and functional roles in health and disease. J Mol Med (Berl), 95(11), 1143-1152. doi: 10.1007/ s00109-017-1573-x 10.1007/s00109-017-1573-x [pii] [PubMed: 28782084]

Farfara D, Lifshitz V, \& Frenkel D (2008). Neuroprotective and neurotoxic properties of glial cells in the pathogenesis of Alzheimer's disease. [Research Support, Non-U.S. Gov't Review]. J Cell Mol Med, 12(3), 762-780. doi: 10.1111/j.1582-4934.2008.00314.x [PubMed: 18363841]

Farfara D, Trudler D, Segev-Amzaleg N, Galron R, Stein R, \& Frenkel D (2011). gamma-Secretase component presenilin is important for microglia beta-amyloid clearance. [Research Support, NonU.S. Gov't]. Ann Neurol, 69(1), 170-180. doi: 10.1002/ana.22191 [PubMed: 21280087]

Farfara D, Tuby H, Trudler D, Doron-Mandel E, Maltz L, Vassar RJ, . . Oron U (2015). Low-level laser therapy ameliorates disease progression in a mouse model of Alzheimer's disease. [Research Support, Non-U.S. Gov't]. J Mol Neurosci, 55(2), 430-436. doi: 10.1007/s12031-014-0354-Z [PubMed: 24994540]

Fiane AE, Videm V, Johansen HT, Mellbye OJ, Nielsen EW, \& Mollnes TE (1999). C1-inhibitor attenuates hyperacute rejection and inhibits complement, leukocyte and platelet activation in an ex vivo pig-to-human perfusion model. [Research Support, Non-U.S. Gov't]. Immunopharmacology, 42(1-3), 231-243. [PubMed: 10408384]

Fouche AS, Saunders EF, \& Craig T (2014). Depression and anxiety in patients with hereditary angioedema. Ann Allergy Asthma Immunol, 112(4), 371-375. doi: 10.1016/j.anai.2013.05.028 S1081-1206(13)00362-1 [pii] [PubMed: 24428960]

Ghebrehiwet B, Kaplan AP, Joseph K, \& Peerschke EI (2016). The complement and contact activation systems: partnership in pathogenesis beyond angioedema. [Review]. Immunol Rev, 274(1), 281289. doi: 10.1111/imr.12469 [PubMed: 27782339]

Ginhoux F, Greter M, Leboeuf M, Nandi S, See P, Gokhan S, . . Merad M (2010). Fate mapping analysis reveals that adult microglia derive from primitive macrophages. Science, 330(6005), 841845. doi: 10.1126/science.1194637 science.1194637 [pii] [PubMed: 20966214]

Gould TD, D. D., Kovacsics CE. (2009). The open field test. Mood and Anxiety Related Phenotypes in Mice, Neuromethods., vol. 42, pp. 1-20. doi: 10.1007/978-1-60761-303-9_1

Graesser D, Solowiej A, Bruckner M, Osterweil E, Juedes A, Davis S, . . Madri JA (2002). Altered vascular permeability and early onset of experimental autoimmune encephalomyelitis in PECAM-1-deficient mice. J Clin Invest, 109(3), 383-392. doi: 10.1172/JCI13595 [PubMed: $11827998]$

Grammas P (2011). Neurovascular dysfunction, inflammation and endothelial activation: implications for the pathogenesis of Alzheimer's disease. J Neuroinflammation, 8, 26. doi: 10.1186/1742-2094-8-26 [PubMed: 21439035]

Guerrero R, Velasco F, Rodriguez M, Lopez A, Rojas R, Alvarez MA, . . del Castillo D (1993). Endotoxin-induced pulmonary dysfunction is prevented by $\mathrm{C} 1$-esterase inhibitor. [Research Support, Non-U.S. Gov't]. J Clin Invest, 91(6), 2754-2760. doi: 10.1172/JCI116516 [PubMed: 8514883]

Guilarte M, Sala-Cunill A, Luengo O, Labrador-Horrillo M, \& Cardona V (2017). The Mast Cell, Contact, and Coagulation System Connection in Anaphylaxis. Front Immunol, 8, 846. doi: 10.3389/fimmu.2017.00846 [PubMed: 28798744]

Haass C (1999). Apoptosis. Dead end for neurodegeneration? Nature, 399(6733), 204-205, 207. doi: 10.1038/20312 [PubMed: 10353238] 
Hack CE, Ogilvie AC, Eisele B, Eerenberg AJ, Wagstaff J, \& Thijs LG (1993). C1-inhibitor substitution therapy in septic shock and in the vascular leak syndrome induced by high doses of interleukin-2. [Review]. Intensive Care Med, 19 Suppl 1, S19-28. [PubMed: 8053997]

Han ED, MacFarlane RC, Mulligan AN, Scafidi J, \& Davis AE 3rd. (2002). Increased vascular permeability in $\mathrm{C} 1$ inhibitor-deficient mice mediated by the bradykinin type 2 receptor. $\mathrm{J}$ Clin Invest, 109(8), 1057-1063. doi: 10.1172/JCI14211 [PubMed: 11956243]

Hecker JM, Loss M, Klempnauer J, \& Winkler M (2002). C1-inhibitor for therapy and prophylaxis of acute vascular rejection of porcine kidneys in cynomolgus monkeys. Transplant Proc, 34(6), 2382. [PubMed: 12270447]

Hellal F, Bonnefont-Rousselot D, Croci N, Palmier B, Plotkine M, \& Marchand-Verrecchia C (2004). Pattern of cerebral edema and hemorrhage in a mice model of diffuse brain injury. [Research Support, Non-U.S. Gov’t]. Neurosci Lett, 357(1), 21-24. doi: 10.1016/j.neulet.2003.12.036 [PubMed: 15036604]

Heydenreich N, Nolte MW, Gob E, Langhauser F, Hofmeister M, Kraft P, . . Kleinschnitz C (2012). $\mathrm{C} 1$-inhibitor protects from brain ischemia-reperfusion injury by combined antiinflammatory and antithrombotic mechanisms. Stroke, 43(9), 2457-2467. doi: 10.1161/STROKEAHA.112.660340] [PubMed: 22744646]

Horstick G, Heimann A, Gotze O, Hafner G, Berg O, Bohmer P, . . Kempski O (1997). Intracoronary application of $\mathrm{C} 1$ esterase inhibitor improves cardiac function and reduces myocardial necrosis in an experimental model of ischemia and reperfusion. Circulation, 95(3), 701-708. [PubMed: 9024160]

Horstick G, Kempf T, Lauterbach M, Bhakdi S, Kopacz L, Heimann A, . . Kempski O (2001). C1esterase-inhibitor treatment at early reperfusion of hemorrhagic shock reduces mesentry leukocyte adhesion and rolling. [Research Support, Non-U.S. Gov't]. Microcirculation, 8(6), 427-433. doi: 10.1038/sj/mn/7800115 [PubMed: 11781815]

Hsieh HL, Wu CY, \& Yang CM (2008). Bradykinin induces matrix metalloproteinase-9 expression and cell migration through a PKC-delta-dependent ERK/Elk-1 pathway in astrocytes. Glia, 56(6), 619632. doi: 10.1002/glia.20637 [PubMed: 18240315]

Hu Z, Ou Y, Duan K, \& Jiang X (2010). Inflammation: a bridge between postoperative cognitive dysfunction and Alzheimer's disease. [Research Support, Non-U.S. Gov't]. Med Hypotheses, 74(4), 722-724. doi: 10.1016/j.mehy.2009.10.040 [PubMed: 19944539]

Iadecola C (2004). Neurovascular regulation in the normal brain and in Alzheimer's disease. Nat Rev Neurosci, 5(5), 347-360. doi: 10.1038/nrn1387 [PubMed: 15100718]

Inamura T, \& Black KL (1994). Bradykinin selectively opens blood-tumor barrier in experimental brain tumors. J Cereb Blood Flow Metab, 14(5), 862-870. doi: 10.1038/jcbfm.1994.108 [PubMed: 8063881]

Jansen PM, Eisele B, de Jong IW, Chang A, Delvos U, Taylor FB Jr., \& Hack CE (1998). Effect of C1 inhibitor on inflammatory and physiologic response patterns in primates suffering from lethal septic shock. [Research Support, Non-U.S. Gov't]. J Immunol, 160(1), 475-484. [PubMed: 9552006]

Joseph K, Tholanikunnel BG, \& Kaplan AP (2009). Factor XII-independent cleavage of highmolecular-weight kininogen by prekallikrein and inhibition by $\mathrm{C} 1$ inhibitor. J Allergy Clin Immunol, 124(1), 143-149. doi: 10.1016/j.jaci.2009.02.006 S0091-6749(09)00232-2 [pii] [PubMed: 19342086]

Kaur C, Rathnasamy G, \& Ling EA (2016). The Choroid Plexus in Healthy and Diseased Brain. J Neuropathol Exp Neurol, 75(3), 198-213. doi: 10.1093/jnen/nlv030nlv030 [pii] [PubMed: 26888305]

Kruyer A, Soplop N, Strickland S, \& Norris EH (2015). Chronic Hypertension Leads to Neurodegeneration in the TgSwDI Mouse Model of Alzheimer's Disease. Hypertension, 66(1), 175-182. doi: 10.1161/HYPERTENSIONAHA.115.05524 [PubMed: 25941345]

Lasek-Bal A, Holecki M, Handzlik-Orlik G, Smertka M, \& Dulawa J (2015). Hereditary angioedema with dominant cerebral symptoms finally leading to chronic disability. Clin Neurol Neurosurg, 135, 38-40. doi: 10.1016/j.clineuro.2015.03.023 S0303-8467(15)00135-3 [pii] [PubMed: 26022712] 
Leeb-Lundberg LM, Marceau F, Muller-Esterl W, Pettibone DJ, \& Zuraw BL (2005). International union of pharmacology. XLV. Classification of the kinin receptor family: from molecular mechanisms to pathophysiological consequences. Pharmacol Rev, 57(1), 27-77. doi: 57/1/27 [pii] 10.1124/pr.57.1.2 [PubMed: 15734727]

Levant A, Levy E, Argaman M, \& Fleisher-Berkovich S (2006). Kinins and neuroinflammation: dual effect on prostaglandin synthesis. European Journal of Pharmacology, 546(1-3), 197-200. doi: S0014-2999(06)00693-5 [pii] 10.1016/j.ejphar.2006.06.074 [PubMed: 16889769]

London A, Cohen M, \& Schwartz M (2013). Microglia and monocyte-derived macrophages: functionally distinct populations that act in concert in CNS plasticity and repair. Front Cell Neurosci, 7, 34. doi: 10.3389/fncel.2013.00034 [PubMed: 23596391]

Mogi M, \& Horiuchi M (2011). Neurovascular coupling in cognitive impairment associated with diabetes mellitus. Circ J, 75(5), 1042-1048. doi: JST.JSTAGE/circj/CJ-11-0121 [pii] [PubMed: 21441696]

Neri S, Giardino F, \& Rizzotto A . (2014). An Unusual Case of Cerebral Oedema. European Journal of Case Reports in Internal Medicine, 1(1). . doi:

Niederau C, Brinsa R, Niederau M, Luthen R, Strohmeyer G, \& Ferrell LD (1995). Effects of C1esterase inhibitor in three models of acute pancreatitis. [Research Support, Non-U.S. Gov't]. Int J Pancreatol, 17(2), 189-196. [PubMed: 7622941]

Nielsen EW, Johansen HT, Gaudesen O, Osterud B, Olsen JO, Hogasen K, . . Mollnes TE (1995). C3 is activated in hereditary angioedema, and $\mathrm{C} 1 / \mathrm{C} 1$-inhibitor complexes rise during physical stress in untreated patients. Scand J Immunol, 42(6), 679-685. [PubMed: 8552992]

Nielsen EW, Johansen HT, Hogasen K, Wuillemin W, Hack CE, \& Mollnes TE (1996). Activation of the complement, coagulation, fibrinolytic and kallikrein-kinin systems during attacks of hereditary angioedema. Immunopharmacology, 33(1-3), 359-360. [PubMed: 8856186]

Nussberger J, Cugno M, Amstutz C, Cicardi M, Pellacani A, \& Agostoni A (1998). Plasma bradykinin in angio-oedema. Lancet, 351(9117), 1693-1697. doi: S0140-6736(97)09137-X [pii] 10.1016/ S0140-6736(97)09137-X [PubMed: 9734886]

O'Callaghan JP, Sriram K, \& Miller DB (2008). Defining “neuroinflammation”. Ann N Y Acad Sci, 1139, 318-330. doi: 10.1196/annals.1432.032 NYAS1139032 [pii] [PubMed: 18991877]

Obasi CN, Cruickshanks KJ, Nondahl DM, Klein BE, Klein R, Nieto FJ, . . Chappell R (2012). Association of Biomarkers for Inflammation, Endothelial Dysfunction and Oxidative Stress with Cognitive Impairment. The Epidemiology of Hearing Loss Study (EHLS). Oxid Antioxid Med Sci, 1(3), 169-173. doi: 10.5455/oams.031212.br.004 [PubMed: 23814681]

Olesen SP, \& Crone C (1986). Substances that rapidly augment ionic conductance of endothelium in cerebral venules. Acta Physiol Scand, 127(2), 233-241. doi: 10.1111/j.1748-1716.1986.tb07898.x [PubMed: 3487916]

Owens T, Bechmann I, \& Engelhardt B (2008). Perivascular spaces and the two steps to neuroinflammation. J Neuropathol Exp Neurol, 67(12), 1113-1121. doi: 10.1097/NEN. 0b013e31818f9ca8 [PubMed: 19018243]

Pauer HU, Renne T, Hemmerlein B, Legler T, Fritzlar S, Adham I, . . Burfeind P (2004). Targeted deletion of murine coagulation factor XII gene-a model for contact phase activation in vivo. Thromb Haemost, 92(3), 503-508. doi: 10.1160/TH04-04-0250 04090503 [pii] [PubMed: 15351846]

Paul J, Strickland S, \& Melchor JP (2007). Fibrin deposition accelerates neurovascular damage and neuroinflammation in mouse models of Alzheimer's disease. J Exp Med, 204(8), 1999-2008. doi: jem.20070304 [pii] 10.1084/jem.20070304 [PubMed: 17664291]

Petersen MA, Ryu JK, \& Akassoglou K (2018). Fibrinogen in neurological diseases: mechanisms, imaging and therapeutics. Nature Reviews Neuroscience, 19(5), 283-301. doi: 10.1038/nrn. 2018.13 [PubMed: 29618808]

Qadri F, Rimmele F, Mallis L, Hauser W, Dendorfer A, Johren O, . . Bader M (2016). Acute hypothalamo-pituitary-adrenal axis response to LPS-induced endotoxemia: expression pattern of kinin type B1 and B2 receptors. Biol Chem, 397(2), 97-109. doi: 10.1515/hsz-2015-0206 [PubMed: 26468906] 
Raslan F, Schwarz T, Meuth SG, Austinat M, Bader M, Renne T, . . Kleinschnitz C (2010). Inhibition of bradykinin receptor $\mathrm{B} 1$ protects mice from focal brain injury by reducing blood-brain barrier leakage and inflammation. J Cereb Blood Flow Metab, 30(8), 1477-1486. doi: 10.1038/jcbfm. 2010.28 jcbfm201028 [pii] [PubMed: 20197781]

Rezai-Zadeh K, Gate D, \& Town T (2009). CNS infiltration of peripheral immune cells: D-Day for neurodegenerative disease? J Neuroimmune Pharmacol, 4(4), 462-475. doi: 10.1007/ s11481-009-9166-2 [PubMed: 19669892]

Rossi V, Bally I, Ancelet S, Xu Y, Fremeaux-Bacchi V, Vives RR, . . Arlaud GJ (2010). Functional characterization of the recombinant human $\mathrm{C} 1$ inhibitor serpin domain: insights into heparin binding. [Research Support, Non-U.S. Gov't]. J Immunol, 184(9), 4982-4989. doi: 10.4049/ jimmunol.0902016 [PubMed: 20351192]

Rothschild AM, \& Gascon LA (1966). Sulphuric esters of polysaccharides as activators of a bradykinin-forming system in plasma. Nature, 212(5068), 1364. [PubMed: 5967019]

Ryu JK, Petersen MA, Murray SG, Baeten KM, Meyer-Franke A, Chan JP, . . Akassoglou K (2015). Blood coagulation protein fibrinogen promotes autoimmunity and demyelination via chemokine release and antigen presentation. Nat Commun, 6, 8164. doi: 10.1038/ncomms9164 ncomms9164 [pii] [PubMed: 26353940]

Sabharwal G, \& Craig T (2015). Recombinant human C1 esterase inhibitor for the treatment of hereditary angioedema due to $\mathrm{C} 1$ inhibitor deficiency (C1-INH-HAE). Expert Rev Clin Immunol, 11(3), 319-327. doi: 10.1586/1744666X.2015.1012502 [PubMed: 25669442]

Sala-Cunill A, Bjorkqvist J, Senter R, Guilarte M, Cardona V, Labrador M, . . Renne T (2015). Plasma contact system activation drives anaphylaxis in severe mast cell-mediated allergic reactions. J Allergy Clin Immunol, 135(4), 1031-1043 e1036. doi: 10.1016/j.jaci.2014.07.057 [PubMed: 25240785]

Sanovich E, Bartus RT, Friden PM, Dean RL, Le HQ, \& Brightman MW (1995). Pathway across blood-brain barrier opened by the bradykinin agonist, RMP-7. Brain Res, 705(1-2), 125-135. doi: 0006-8993(95)01143-9 [pii] [PubMed: 8821743]

Satoh J, Kino Y, Asahina N, Takitani M, Miyoshi J, Ishida T, \& Saito Y (2016). TMEM119 marks a subset of microglia in the human brain. Neuropathology, 36(1), 39-49. doi: 10.1111/neup.12235 [PubMed: 26250788]

Schapira M, Scott CF, \& Colman RW (1982). Contribution of plasma protease inhibitors to the inactivation of kallikrein in plasma. [Research Support, Non-U.S. Gov't Research Support, U.S. Gov't, P.H.S.]. J Clin Invest, 69(2), 462-468. [PubMed: 6173399]

Schapira M, Silver LD, Scott CF, Schmaier AH, Prograis LJ Jr., Curd JG, \& Colman RW (1983). Prekallikrein activation and high-molecular-weight kininogen consumption in hereditary angioedema. N Engl J Med, 308(18), 1050-1053. doi: 10.1056/NEJM198305053081802 [PubMed: 6601240]

Scherer RU, Giebler RM, Schmidt U, Paar D, \& Kox WJ (1996). The influence of C1-esterase inhibitor substitution on coagulation and cardiorespiratory parameters in an endotoxin-induced rabbit model of hypercoagulability. Semin Thromb Hemost, 22(4), 357-366. doi: 10.1055/ s-2007-999032 [PubMed: 8944422]

Schmaier AH, \& McCrae KR (2007). The plasma kallikrein-kinin system: its evolution from contact activation. [Research Support, N.I.H., Extramural Review]. J Thromb Haemost, 5(12), 2323-2329. doi: 10.1111/j.1538-7836.2007.02770.x [PubMed: 17883591]

Schubert-Unkmeir A, Konrad C, Slanina H, Czapek F, Hebling S, \& Frosch M (2010). Neisseria meningitidis induces brain microvascular endothelial cell detachment from the matrix and cleavage of occludin: a role for MMP-8. PLoS Pathog, 6(4), e1000874. doi: 10.1371/journal.ppat.1000874 [PubMed: 20442866]

Seo JS, Zhong P, Liu A, Yan Z, \& Greengard P (2018). Elevation of p11 in lateral habenula mediates depression-like behavior. Mol Psychiatry, 23(5), 1113-1119. doi: 10.1038/mp.2017.96 mp201796 [pii] [PubMed: 28507317]

Shechter R, London A, Varol C, Raposo C, Cusimano M, Yovel G, . . Schwartz M (2009). Infiltrating blood-derived macrophages are vital cells playing an anti-inflammatory role in recovery from spinal cord injury in mice. PLoS Med, 6(7), e1000113. doi: 10.1371/journal.pmed.1000113 [PubMed: 19636355] 
Simen AA, Bordner KA, Martin MP, Moy LA, \& Barry LC (2011). Cognitive dysfunction with aging and the role of inflammation. Ther Adv Chronic Dis, 2(3), 175-195. doi: 10.1177/2040622311399145 [PubMed: 23251749]

Siso S, Jeffrey M, \& Gonzalez L (2010). Sensory circumventricular organs in health and disease. Acta Neuropathol, 120(6), 689-705. doi: 10.1007/s00401-010-0743-5 [PubMed: 20830478]

Taheri S, Gasparovic C, Huisa BN, Adair JC, Edmonds E, Prestopnik J, . . Rosenberg GA (2011). Blood-brain barrier permeability abnormalities in vascular cognitive impairment. Stroke, 42(8), 2158-2163. doi: 10.1161/STROKEAHA.110.611731 STROKEAHA.110.611731 [pii] [PubMed: 21719768]

Takechi R, Lam V, Brook E, Giles C, Fimognari N, Mooranian A, . . Mamo JCL (2017). Blood-Brain Barrier Dysfunction Precedes Cognitive Decline and Neurodegeneration in Diabetic Insulin Resistant Mouse Model: An Implication for Causal Link. Front Aging Neurosci, 9, 399. doi: 10.3389/fnagi.2017.00399 [PubMed: 29249964]

Tassani P, Kunkel R, Richter JA, Oechsler H, Lorenz HP, Braun SL, . . Lange R (2001). Effect of C1esterase-inhibitor on capillary leak and inflammatory response syndrome during arterial switch operations in neonates. [Clinical Trial Randomized Controlled Trial]. J Cardiothorac Vasc Anesth, 15(4), 469-473. doi: 10.1053/jcan.2001.24989 [PubMed: 11505352]

Thompson RE, Mandle R Jr., \& Kaplan AP (1978). Characterization of human high molecular weight kininogen. Procoagulant activity associated with the light chain of kinin-free high molecular weight kininogen. J Exp Med, 147(2), 488-499. [PubMed: 75240]

Tracey KJ (2016). Reflexes in Immunity. Cell, 164(3), 343-344. doi: 10.1016/j.cell.2016.01.018 S0092-8674(16)00058-1 [pii] [PubMed: 26824649]

Vainchtein ID, Vinet J, Brouwer N, Brendecke S, Biagini G, Biber K, . . Eggen BJ (2014). In acute experimental autoimmune encephalomyelitis, infiltrating macrophages are immune activated, whereas microglia remain immune suppressed. Glia, 62(10), 1724-1735. doi: 10.1002/glia.22711 [PubMed: 24953459]

Waeber B, Nussberger J, Brunner HR, de Agostini A, \& Schapira M (1984). [Role of bradykinin in hypotension induced by the active factor derived from factor XII]. Schweiz Med Wochenschr, 114(48), 1749-1751. [PubMed: 6098010]

Walker K, Perkins M, \& Dray A (1995). Kinins and kinin receptors in the nervous system. Neurochem Int, 26(1), 1-16; discussion 17-26. doi: 019701869400114A [pii] [PubMed: 7787759]

Wang L, Du Y, Wang K, Xu G, Luo S, \& He G (2016). Chronic cerebral hypoperfusion induces memory deficits and facilitates Abeta generation in C57BL/6J mice. Exp Neurol, 283(Pt A), 353-364. doi: 10.1016/j.expneurol.2016.07.006 S0014-4886(16)30205-9 [pii] [PubMed: 27421879]

Weiss R, Lifshitz V, \& Frenkel D (2011). TGF-beta1 affects endothelial cell interaction with macrophages and $\mathrm{T}$ cells leading to the development of cerebrovascular amyloidosis. [Research Support, Non-U.S. Gov't]. Brain Behav Immun, 25(5), 1017-1024. doi: 10.1016/j.bbi. 2010.11.012 [PubMed: 21112386]

Wilson EH, Weninger W, \& Hunter CA (2010). Trafficking of immune cells in the central nervous system. J Clin Invest, 120(5), 1368-1379. doi: 10.1172/JCI4191141911 [pii] [PubMed: 20440079]

Wu F, Zou Q, Ding X, Shi D, Zhu X, Hu W, ... Zhou H (2016). Complement component C3a plays a critical role in endothelial activation and leukocyte recruitment into the brain. $\mathbf{J}$ Neuroinflammation, 13, 23. doi: 10.1186/s12974-016-0485-y 10.1186/s12974-016-0485-y [pii] [PubMed: 26822321]

Zamolodchikov D, Chen ZL, Conti BA, Renne T, \& Strickland S (2015). Activation of the factor XIIdriven contact system in Alzheimer's disease patient and mouse model plasma. Proc Natl Acad Sci U S A, 112(13), 4068-4073. doi: 10.1073/pnas.1423764112 [PubMed: 25775543]

Ziccardi RJ, \& Cooper NR (1979). Active disassembly of the first complement component, C-1, by C-1 inactivator. J Immunol, 123(2), 788-792. [PubMed: 110880]

Zlokovic BV (2008). The blood-brain barrier in health and chronic neurodegenerative disorders. Neuron, 57(2), 178-201. doi: 10.1016/j.neuron.2008.01.003 S0896-6273(08)00034-2 [pii] [PubMed: 18215617] 
Zwijnenburg PJ, van der Poll T, Florquin S, Polfliet MM, van den Berg TK, Dijkstra CD, . . van Furth AM (2007). C1 inhibitor treatment improves host defense in pneumococcal meningitis in rats and mice. J Infect Dis, 196(1), 115-123. doi: 10.1086/518609 [PubMed: 17538891] 


\section{Main points}

Knockdown of circulating $\mathrm{C} 1$ inhibitor induces immune activation through the bradykinin pathway, resulting in hypotension, blood-brain barrier permeability, proinflammatory glial cell activation, immune cell infiltration, and behavioral deficits. 
a.

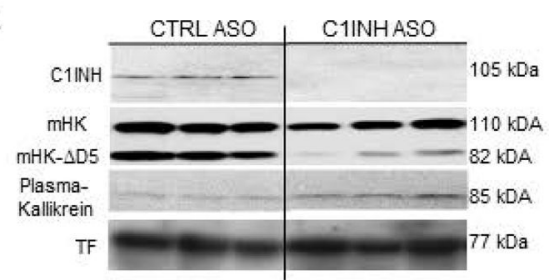

b.

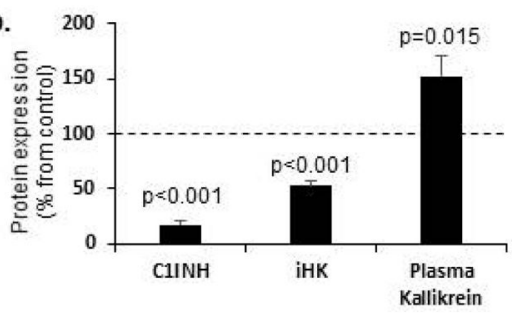

g.

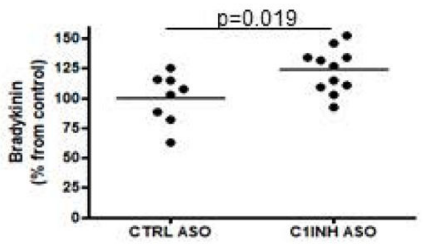

h.

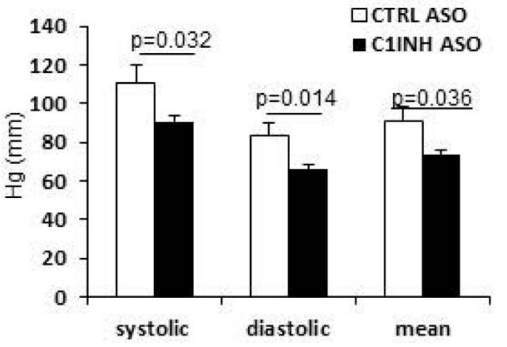

c.

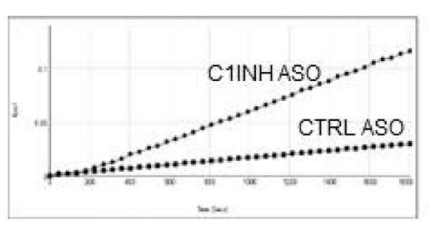

d.

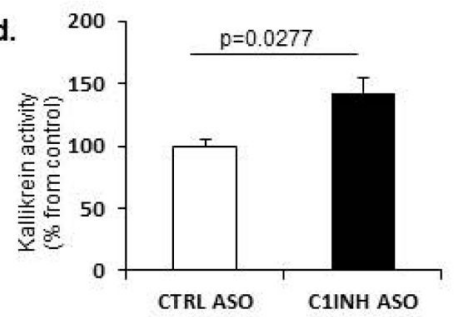

i.

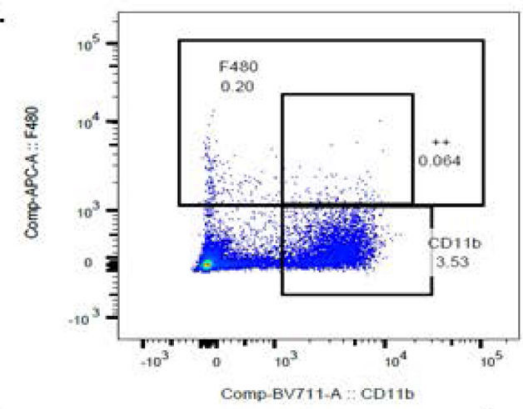

j.

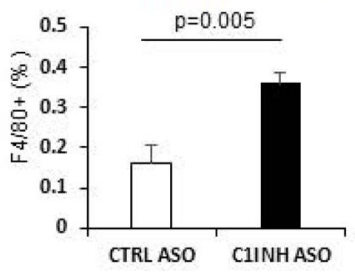

e.

f.

k.
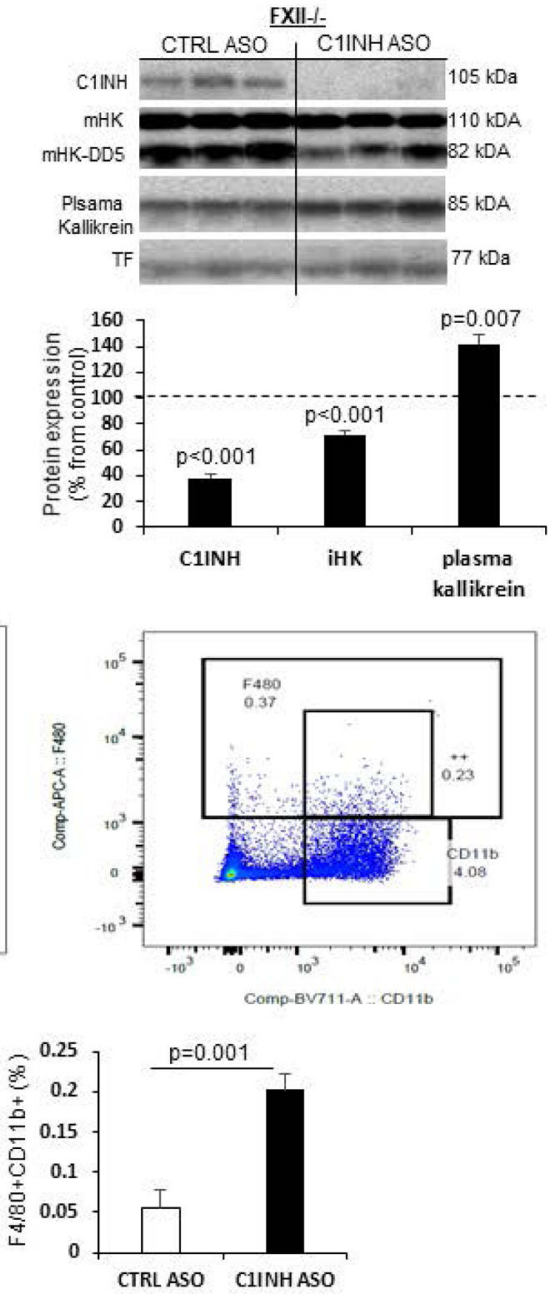

Figure 1.

Increased KKS activation, bradykinin production, and hypotension in C1INH ASO treated mice.Representative immunoblots (a) and quantification (b) show significantly decreased levels of plasma C1INH ( $100 \pm 8.79 \%$ vs. $17.26 \pm 4.27 \%$, $\mathrm{T}(8.152,34), \mathrm{p}<0.001, \mathrm{n}=17-19 /$ group), intact mouse $\mathrm{HK}(\mathrm{mHK} ; 110 \mathrm{kDa}$ and $85 \mathrm{kDa})(100 \pm 9.08 \%$ vs. $52.72 \pm 4.18 \%$, $\mathrm{T}(4.547,34), \mathrm{p}<0.001, \mathrm{n}=17-19$ /group), and increased plasma kallikrein (100+10.7\% vs. $152.3 \pm 17.62 \%, \mathrm{~T}(2.627,22), \mathrm{p}=0.015, \mathrm{n}=11-13$ /group) normalized to transferrin, under reduced conditions, from mice treated with C1INH ASO vs CTRL ASO. Representative kallikrein activity plot (c) and quantification (d) shows a significant increase in KKS activity in C1INH ASO vs CTRL ASO (100 $\pm 4.54 \%$ vs. $142.6 \pm 12.21 \%$, T $(2.504,12), \mathrm{p}=0.0277$, $\mathrm{n}=5-9 /$ group). Representative immunoblots (e) and quantification (f) of plasma from FXII-/mice treated with C1INH ASO vs CTRL ASO show decreased C1INH (100 $\pm 8.8 \%$ vs. $38.29 \pm 3.5 \%, \mathrm{~T}(5.905,7), \mathrm{p}<0.001, \mathrm{n}=4-5 /$ group $)$ and $\mathrm{iHK}(100 \pm 2.32 \%$ vs. $71.66 \pm 3.35 \%$, $\mathrm{T}(7.169,7), \mathrm{p}<0.001, \mathrm{n}=4-5 /$ group $)$ and increased plasma kallikrein ( $100 \pm 6.62 \%$ vs. $141.97 \pm 6.64 \%, \mathrm{~T}(4.415,7), \mathrm{p}=0.007, \mathrm{n}=4-5 /$ group $)$ normalized to transferrin, under reduced conditions. (g) ELISA data shows a significant increase in plasma bradykinin of C1INH ASO vs. CTRL ASO (100 $\pm 7.3 \%$, vs. $123.4 \pm 5.64 \%, \mathrm{~T}(2.574,17), \mathrm{p}=0.019, \mathrm{n}=8-11$ /group). (h) Decreased blood pressure measurements from C1INH ASO vs. CTRL ASO mice 
(systolic (111.18 $\pm 9.05 \mathrm{Hg}(\mathrm{mm})$ vs. $90.8 \pm 2.97 \mathrm{Hg}(\mathrm{mm}), \mathrm{T}(2.319,18), \mathrm{p}=0.032)$; diastolic $(83.49 \pm 6.49 \mathrm{Hg}(\mathrm{mm})$ vs. $65.81 \pm 2.63 \mathrm{Hg}(\mathrm{mm}), \mathrm{T}(2.704,18), \mathrm{p}=0.014)$; and mean $(90.85 \pm 7.74 \mathrm{Hg}(\mathrm{mm})$ vs. $73.83 \pm 2.59 \mathrm{Hg}(\mathrm{mm}), \mathrm{T}(2.257,18), \mathrm{p}=0.036),(\mathrm{n}=9-11 /$ group$)$. Representative FACS dot-plots (i) and quantifications (j-k) show F4/80+ $(0.161 \pm 0.043 \%$ vs. $0.36 \pm 0.02 \%, \mathrm{~T}(3.76,8), \mathrm{p}=0.005, \mathrm{n}=5$ /group) and $\mathrm{F} 4 / 80+\mathrm{CD} 11 \mathrm{~b}+$ cells are significantly increased $(0.054 \pm 0.02 \%$ vs. $0.2 \pm 0.019 \%, \mathrm{~T}(5.001,8), \mathrm{p}=0.001, \mathrm{n}=5 /$ group $)$ in peritoneal macrophages from C1INH ASO vs CTRL ASO mice. Data are shown as mean \pm SEM and were analyzed by Students t-test. 
a.

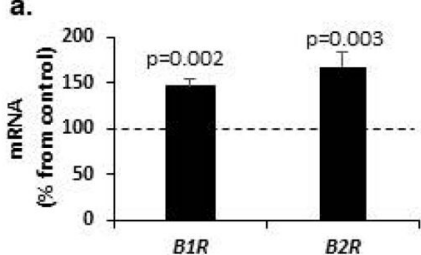

b.
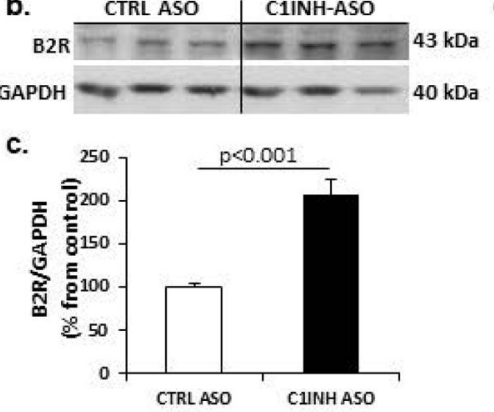

i.

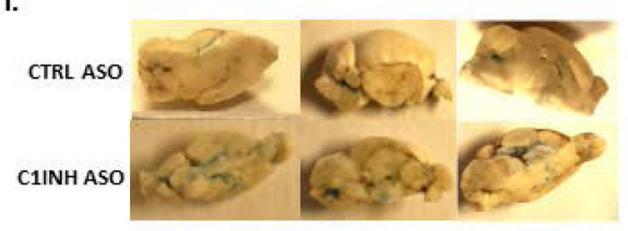

j.

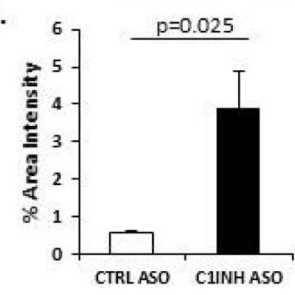

d.

e.
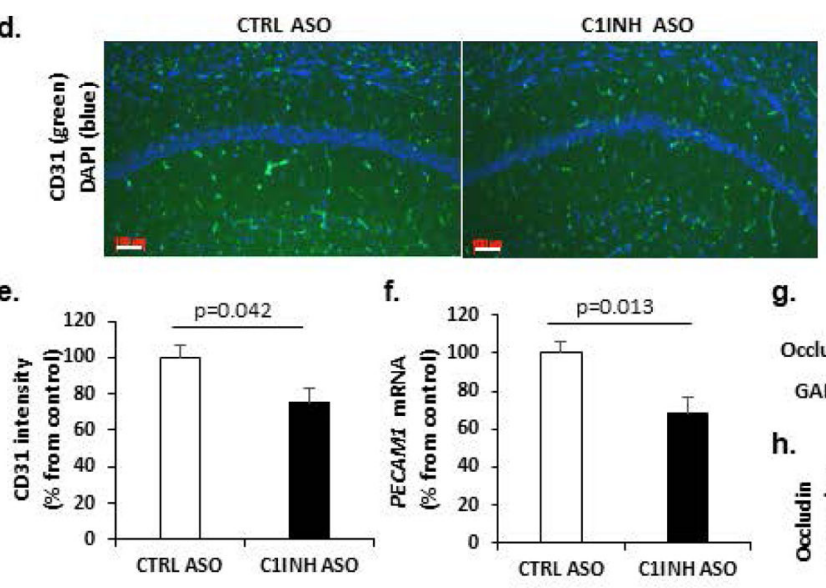

f.

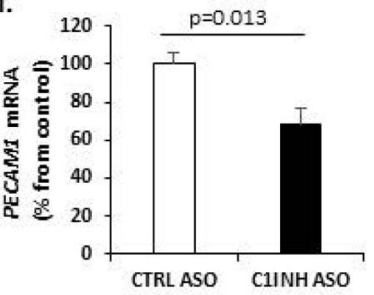

I. CD31 (green) Fibrin(ogen) (red)

CTRL ASO

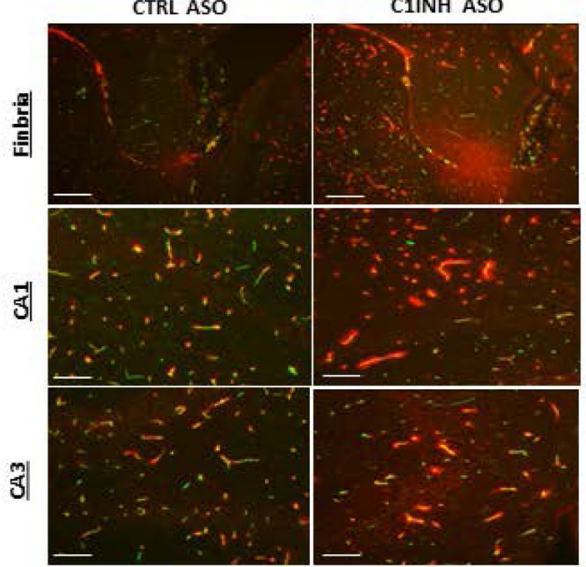

g.

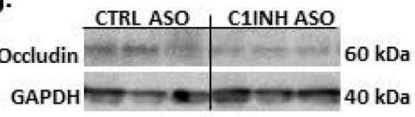

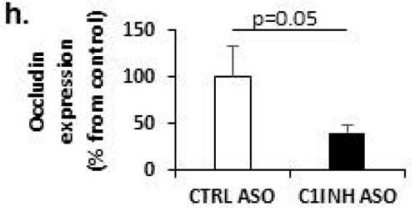

m.

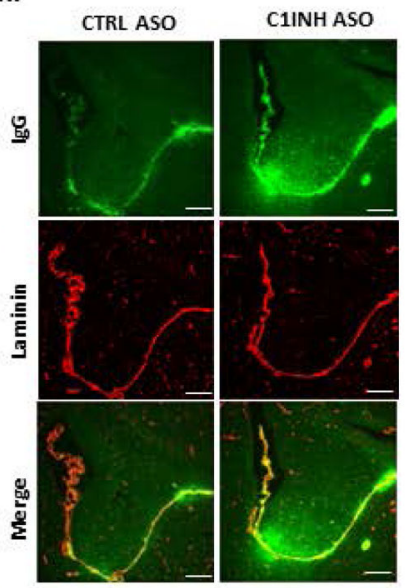

Figure 2.

Knockdown of circulating C1INH leads to activation of the bradykinin pathway and loss of BBB integrity. (a) RT-PCR of coronal brain samples show elevated gene expression of B1R $(100 \pm 6.86 \%$ vs. $145.99 \pm 9.02 \%, \mathrm{~T}(4.058,10), \mathrm{p}=0.002, \mathrm{n}=6 /$ group $)$ and $\mathrm{B} 2 \mathrm{R}(100 \pm 3.98 \%$ vs. $167.44 \pm 16.67 \%, \mathrm{~T}(3.493,14) \mathrm{p}=0.003, \mathrm{n}=7-9 /$ group $)$ from C1INH ASO- vs. CTRL ASOtreated mice. Representative immunoblots (b) and quantification (c) show a 2-fold increase $(100 \pm 3.95 \%$ vs. $206.75 \pm 17.85 \%, T(5.838,8), \mathrm{p}<0.001, \mathrm{n}=5$ /group) of B2R expression from coronal brain homogenates normalized to GAPDH from C1INH ASOcompared to CTRL ASO-treated mice. (d,e) CD31 staining decreased in CA1 region of C1INH ASO- vs. CTRL ASO-treated mice $(100 \pm 7.29 \%$ vs. $75.67 \pm 7.75 \%, \mathrm{~T}(2.228,14), \mathrm{p}=0.042, \mathrm{n}=7-9 /$ group; bar $=$ $100 \mu \mathrm{m})$. (f) PECAM1 gene expression is decreased $(100 \pm 6.54 \%$ vs. $68.56 \pm 8.27 \%$, $\mathrm{T}(2.98$, 10), $\mathrm{p}=0.013, \mathrm{n}=6$ /group) in brains of C1INH ASO vs. CTRL ASO-treated mice.

Representative immunoblots (g) and quantification (h) show a decrease in occludin $(100 \pm 32.69 \%$ vs. $40.64 \pm 7.73 \%, \mathrm{~T}(2.08,15), \mathrm{p}=0.055, \mathrm{n}=7-10$ /group $)$ in C1INH ASO vs. CTRL ASO-treated mice. (i,j) Significant increase in Evans blue staining in brains of C1INH ASO vs. CTRL ASO-treated mice $(0.5723 \pm 0.0735 \%$ vs. $3.921 \pm 0.9570 \%, \mathrm{~T}(3.489$, $4, \mathrm{p}=0.025, \mathrm{n}=3$ /group). (k) Evans blue staining (red) in the brain parenchyma and the lateral ventricle. Blue, DAPI staining (bars $=100 \mu \mathrm{m}$ ). Images of CA1 and CA3 brain regions from 
CTRL ASO and C1INH ASO-treated mice stained with (1) anti-CD31 (green) and antifibrin(ogen) (red) or (m) anti-IgG (green) and anti-laminin (red) antibodies in the lateral ventricle and fimbria. Data are shown as mean \pm SEM and were analyzed by Students t-test. 
a.

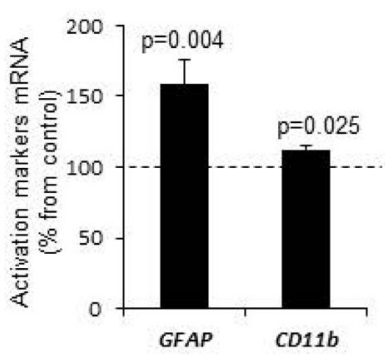

e.

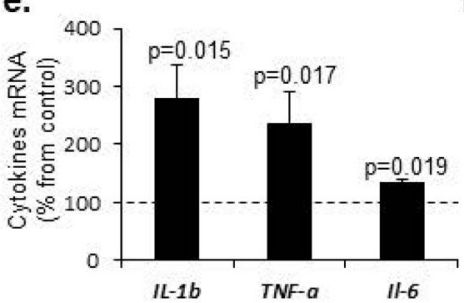

b.

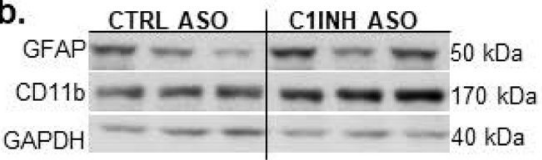

c.

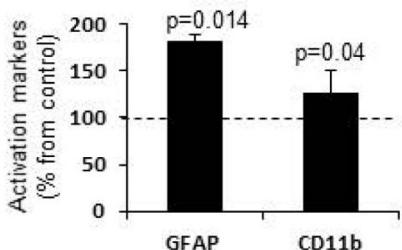

d.

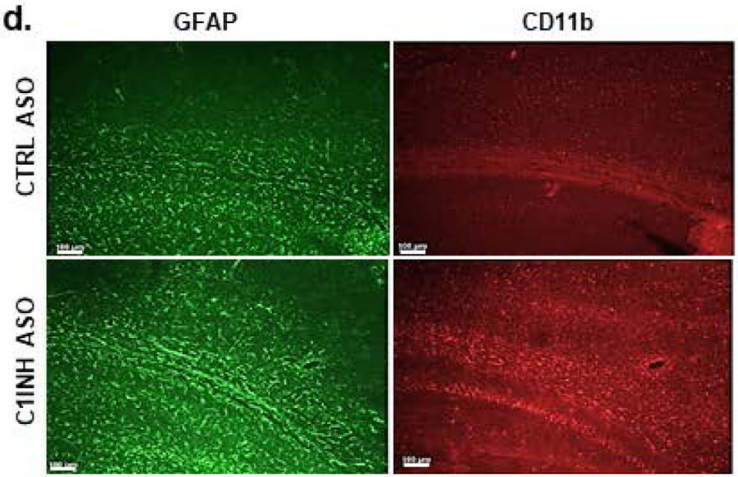

f.

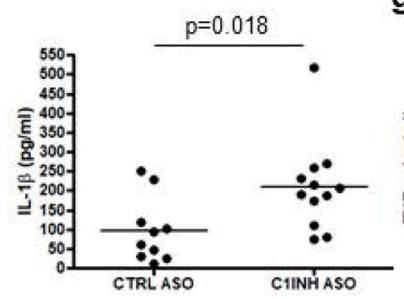

g.

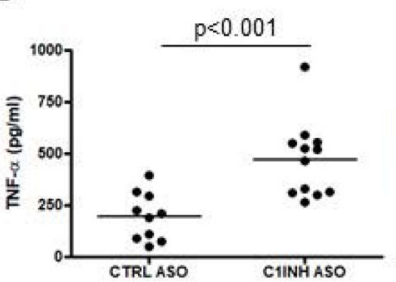

h.

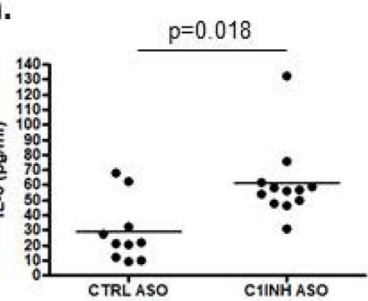

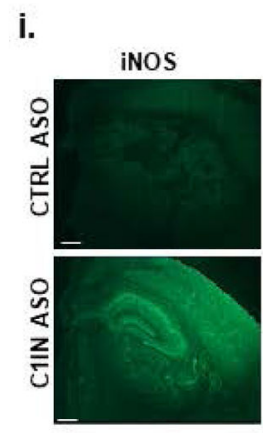

j. CTRL ASO \begin{tabular}{c|c} 
iNOS -- & $= \pm=95 \mathrm{kDa}$ \\
GAPDH - - & $--\longrightarrow 40 \mathrm{kDa}$
\end{tabular}

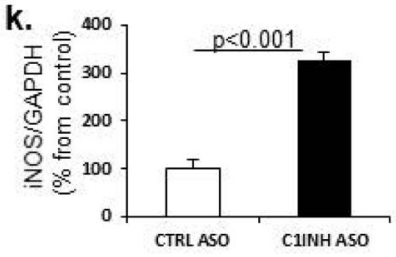

I.

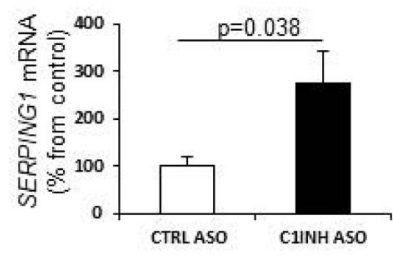

m.

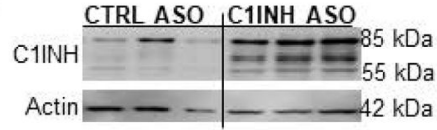

n.

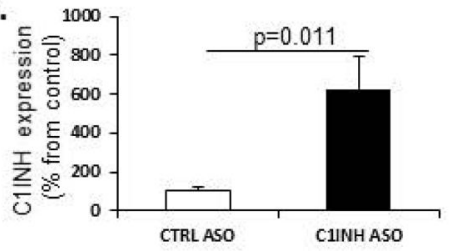

Figure 3.

Glial cell activation towards a pro-inflammatory response. (a) Increased gene expression of GFAP $(100.0 \pm 4.944 \%$ vs. $159.0 \pm 17.25 \%, \mathrm{~T}(3.286,18), \mathrm{p}=0.004, \mathrm{n}=10$ /group $)$ and CD11b $(100.0 \pm 3.871 \%$ vs. $112.3 \pm 3.142 \%, \mathrm{~T}(2.438,19), \mathrm{p}=0.025, \mathrm{n}=11-10$ /group $)$ in the cortex of mice treated with C1INH ASO vs.CTRL ASO. (b) Representative immunoblot (b) and quantification (c) show increased expression of GFAP (100 $\pm 7.14 \%$, vs. $181.22 \pm 25.19 \%$, $\mathrm{T}(3.101,8), \mathrm{p}=0.014, \mathrm{n}=5 /$ group $)$ and $\mathrm{CD} 11 \mathrm{~b}(126.3 \pm 10 \%$ vs. $100 \pm 3.94 \%, \mathrm{~T}(2.446,8)$, $\mathrm{p}=0.04, \mathrm{n}=5 /$ group$)$ in the cortex of C1INH ASO vs. CTRL ASO-treated mice. (d) Representative GFAP and CD11b staining in the cortex of C1INH ASO vs. CTRL ASO treated mice (scale bars $=100 \mu \mathrm{m})$. (e) IL-1 $\beta(100.0 \pm 12.65 \%$ vs. $296.4 \pm 49.66 \%, \mathrm{~T}(3.647$, 17), $\mathrm{p}=0.002, \mathrm{n}=9-10 /$ group $)$, TNF-a $(100.0 \pm 19.31 \%$ vs. $245.1 \pm 63.12 \%, \mathrm{~T}(2.108,19)$, $\mathrm{p}=0.017, \mathrm{n}=10-11)$, and IL-6 ( $100 \pm 12.9 \%$ vs. $133.70 \pm 7.06 \%, \mathrm{p}=0.0397, \mathrm{n}=5$-6/group $)$ gene expression in whole brains of C1INH ASO treated mice was increased compared to CTRL ASO treated mice ( $\mathrm{n}=5-7 /$ group). ELISA shows increased expression of (f) IL-1 $\beta$ $(97.11 \pm 26.18 \mathrm{pg} / \mathrm{ml}$ vs. $209.6 \pm 33.65 \mathrm{pg} / \mathrm{ml}, \mathrm{T}(2.557,20), \mathrm{p}=0.018, \mathrm{n}=10-12, \mathrm{cv}=85.26 \%$ CTRL ASO, 55.6\% C1INH ASO), (g) TNF-a $(195.5 \pm 36.24 \mathrm{pg} / \mathrm{ml}$ vs. $471.5 \pm 53.41 \mathrm{pg} / \mathrm{ml}$, $\mathrm{T}(4.099,20), \mathrm{p}<0.001, \mathrm{n}=10-12, \mathrm{cv}=73.1 \%$ CTRL ASO, 41.18\% C1INH ASO), and (h) IL-6 $(28.47 \pm 6.58 \mathrm{pg} / \mathrm{ml}$ vs. $60.67 \pm 7.214 \mathrm{pg} / \mathrm{ml}, \mathrm{T}(3.241,20), \mathrm{p}=0.0041, \mathrm{n}=10-12$, 
$\mathrm{cv}=58.62 \%$ CTRL ASO, 39.23\% C1INH ASO) in C1INH ASO treated mice vs. control group. (i) iNOS immunofluorescence (scale bar $=1000 \mu \mathrm{m}$ ) and immunoblot $(\mathrm{j})$ from C1INH ASO treated mice compared to CTRL ASO treated mice. (k) Elevated protein expression of iNOS $(100.1 \pm 18.52 \%$ vs. $326.32 \pm 18.64 \%$, $\mathrm{T}(8.608,10) \mathrm{p}<0.001, \mathrm{n}=6$ /group $)$ in C1INH ASO treated mice compared to controls. (1) Increased levels of SERPING1 gene expression $(100.0 \pm 15.85 \%$ vs. $239.0 \pm 54.69 \%, \mathrm{~T}(2.44,10), \mathrm{p}=0.0348)$ in whole brains of C1INH ASO compared to CTRL ASO. Representative (m) and quantification (n) of C1INH immunoblot show increased expression $(100 \pm 23.87 \%$ vs. $627.32 \pm 170.5 \%, \mathrm{~T}(3.064,10)$, $\mathrm{p}=0.012, \mathrm{n}=6$ /group) from whole brain homogenates of C1INH ASO compared CTRL ASO. Data are shown as mean \pm SEM and were analyzed by Students t-test. 
a.

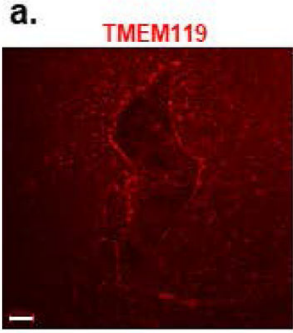

CD11b

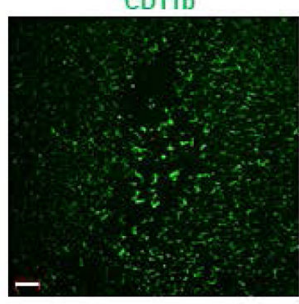

TMEM119/CD11b

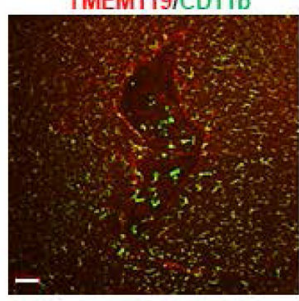

b.

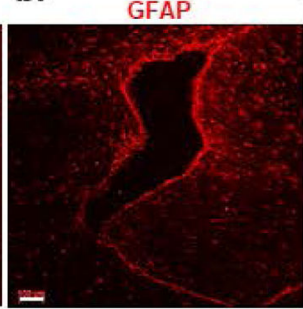

CD68

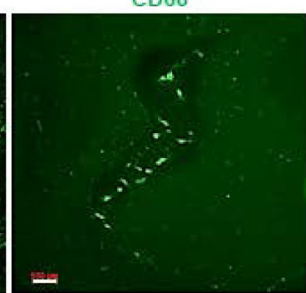

GFAP/CD68

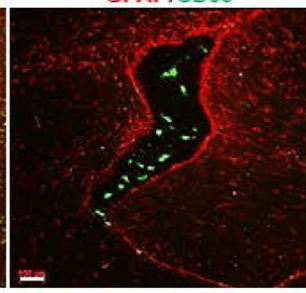

c.

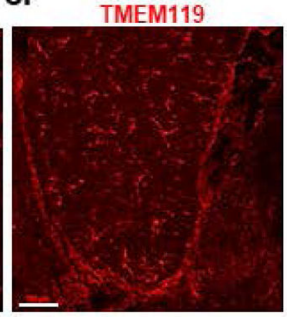

CD11b

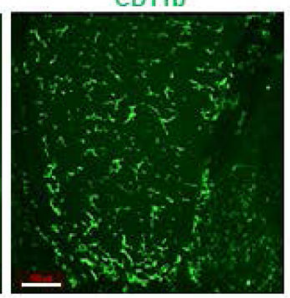

TMEM119/CD11b

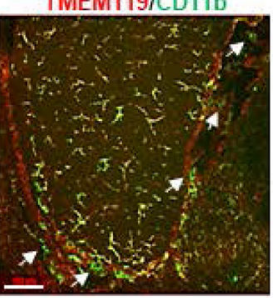

d. CTRL ASO

CIINHASO

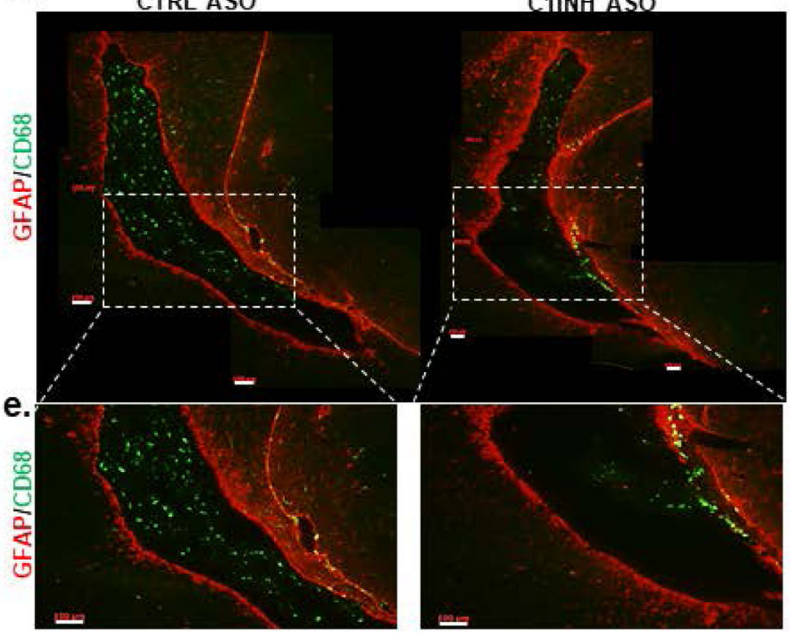

f.

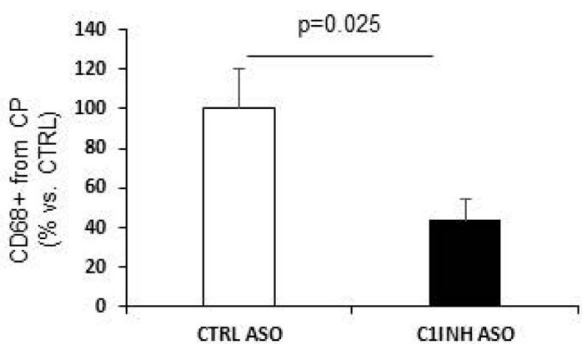

Figure 4.

Myeloid cells infiltrate through ventricular spaces in brains of C1INH-ASO treated mice. (a) Representative images of the lateral ventricle (LV) of CTRL ASO-treated mice stained for TMEM119 (red) and CD11b (green). Merged image shows that LV has no TMEM119 but contains CD11b+ cells. (b) Representative image of GFAP (red) and CD68 (green). Merged image shows CD68+ cells inside the LV, while GFAP+ cells are not. (c) Representative image of TMEM119 (red) and CD11b (green). Merged image shows TMEM119+/CD11b+ in the fimbria of the hippocampus, but only $\mathrm{CD} 11 \mathrm{~b}+$ (white arrows) in the ventricle and interstitial spaces. (d) Representative stitched images of the LV at bregma approximately -2.3 mm stained for CD68 (green) and GFAP (red) in CTRL ASO- and C1INH ASO-treated mice. (e) Enlarged images of the LV shown in d, show migrating CD68+ cells in the LV wall of C1INH ASO-treated mouse brain but not CTRL-ASO treated brain. (f) Quantification of CD68 shows a decreased signal $(100 \pm 20.19 \%$ vs. $43.94 \pm 10.46 \%, T(2.465,16), \mathrm{p}=0.025$, $\mathrm{n}=9 /$ group) in CINH ASO-treated mouse brains compared to controls (scale bar $=100 \mu \mathrm{m}$ ). Data are shown as mean \pm SEM and were analyzed by Students t-test. 
a.
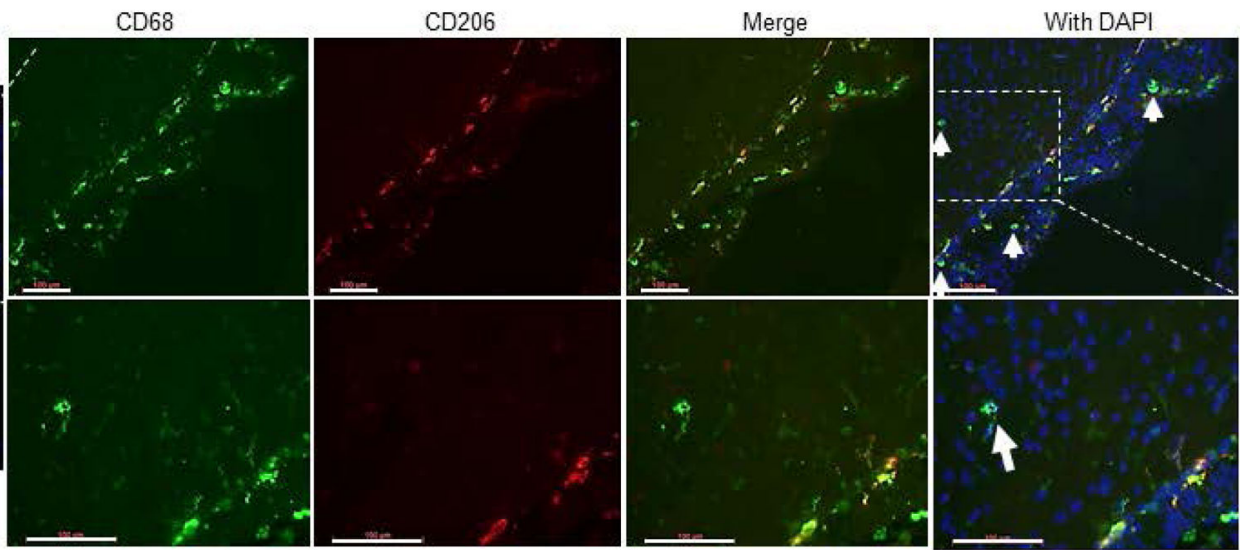

b.

CD68

CD206

Merge

With DAPI
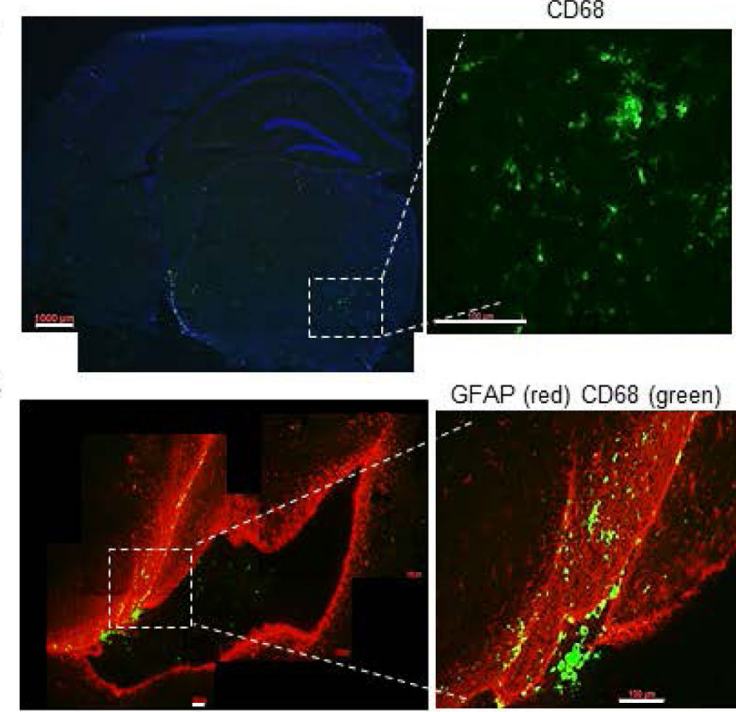

GFAP (red) CD68 (green)

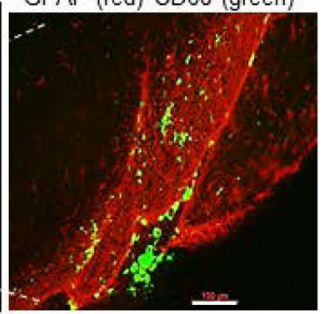

d.

TMEM119
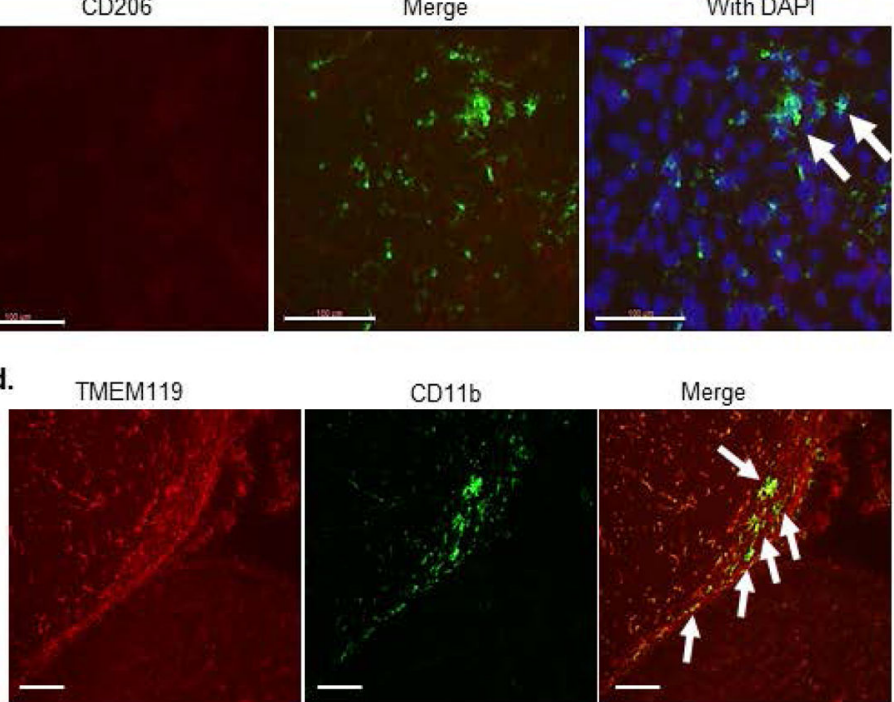

CD11b

Merge

Figure 5.

Myeloid cells infiltrate in different brain regions of C1INH ASO-treated mice. (a)

Representative image of the ventricular wall stained for CD68 (green), CD206 (red), and DAPI (blue) shows infiltrating blood-derived cells that are not co-localized with CD206 (white arrows) (scale bar $=100 \mu \mathrm{m}$ ). (b) Representative image of CD68+ cells that are not co-localized with CD206 in the brain parenchyma (scale bar $=100 \mu \mathrm{m})$. (c) Representative image for GFAP (red) and CD68 (green) in bregma $-2.54 \mathrm{~mm}$ of the brain from C1INH ASO-treated mice showing migrating CD68+ cells in the optic tract (scale bar $=100 \mu \mathrm{m}$ ). (d) TMEM119 (red) does not colocalize with CD11b (green) in the optic tract of C1INH ASO-treated mice brain (scale bar $=100 \mu \mathrm{m})$. 
a.

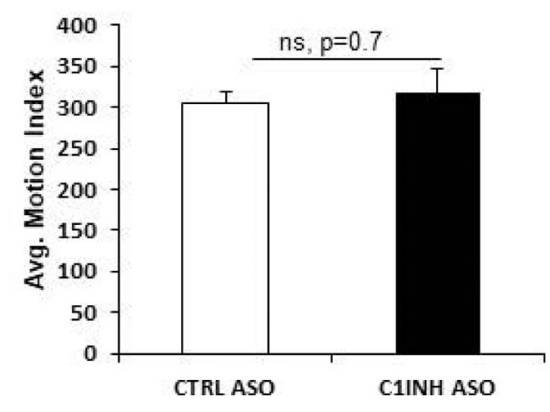

d.

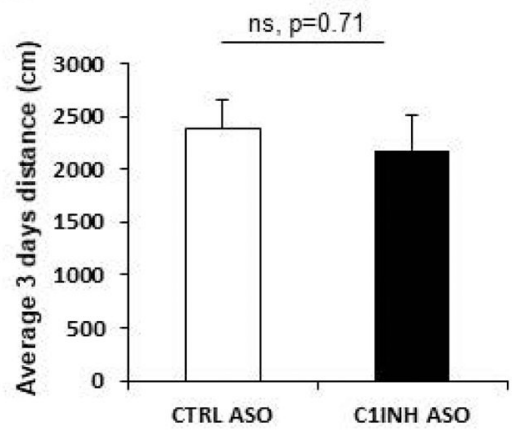

b.

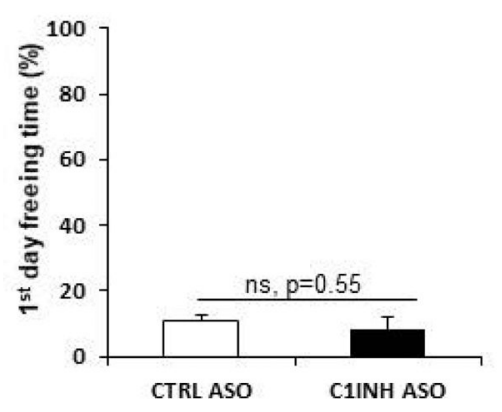

e.

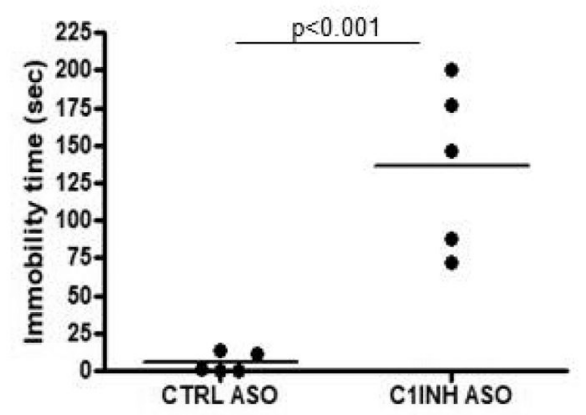

Figure 6.

C1INH ASO-treated mice have behavioral deficits without locomotor impairment. (a) Motion analysis of mice prior to on fear conditioning training $(304.58 \pm 14.22 \mathrm{vs.}$

317.29 $\pm 28.7, \mathrm{p}=0.7, \mathrm{n}=5$ /group). (b) Percent time immobile (post-shock) on Day 1 of fear conditioning ( $10.85 \pm 2.02 \%$ vs. $8.49 \pm 3.3 \%, \mathrm{p}=0.55, \mathrm{n}=5 /$ group). (c) Decreased freezing time on Day 2 of fear conditioning in C1INH ASO-treated mice compared to control group (74.8 $\pm 6.52 \%$ vs. $48.02 \pm 6.137 \%, \mathrm{~T}(2.942,17), \mathrm{p}=0.009, \mathrm{n}=8-11 /$ group $)$. (d) Distance traveled over three days in an open field $(2375.16 \pm 180 \mathrm{~cm}$. vs. $2175.53 \pm 200 \mathrm{~cm}$., $\mathrm{p}=0.7$, $\mathrm{n}=3-6$ /group). (e) Time spent immobile is significantly greater $(5.358 \pm 2.796 \mathrm{sec}$. vs. $136.7 \pm 24.88$ sec., $\mathrm{T}(5.24,8), \mathrm{p}<0.001, \mathrm{n}=5$ /group) in C1INH ASO-treated mice compared to the control group. Data are shown as mean \pm SEM and were analyzed by Students t-test. 

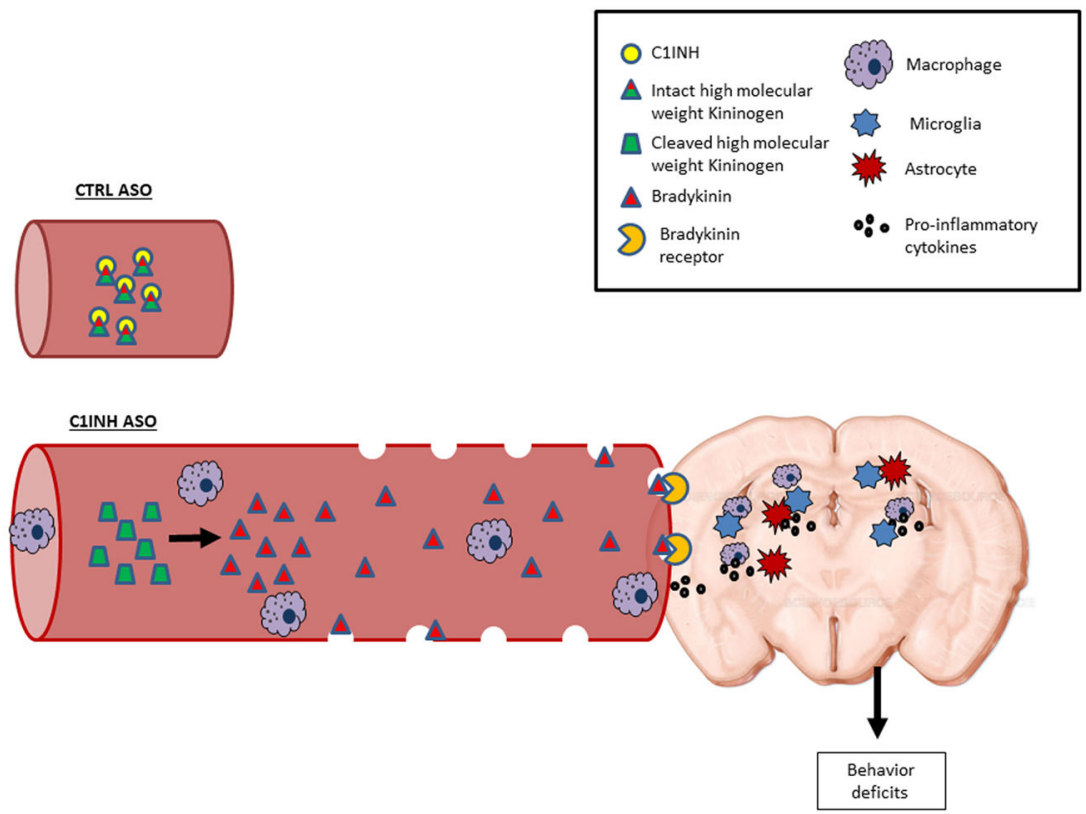

Table/Scheme 1. 